\title{
Technological Innovation, Sustainable Green Practices and SMEs Sustainable Performance in Times of Crisis (COVID-19 pandemic)
}

\author{
Mansour Naser Alraja ${ }^{1} \cdot$ Rabia Imran² $\cdot$ Basel M. Khashab ${ }^{3} \cdot$ Mahmood Shah $^{4}$
}

Accepted: 19 January 2022 / Published online: 9 February 2022

(c) The Author(s) 2022

\begin{abstract}
COVID-19 restrictions significantly affected SMEs, which have faced many challenges to their sustainability within this fragile new environment. This study proposes a holistic framework of sustainable performance by interrelating factors showing robust associations to produce this effect' for achieving sustainable performance in SMEs, through integrating the Technology Organisation Environment (TOE) and Resource Based View (RBV) models, to test how sustainable green practices can process the TOE factors when affecting sustainable performance. The research focuses on SMEs with worldwide employees and involves data collected from a range of different employees belonging to four different managerial levels. The process incorporated the analysis of 669 questionnaires to test the proposed hypotheses using structural equation modeling. Findings suggest that, together, TOE factors represent crucial inputs for green practices such as green training, green performance appraisal, that, in turn, mean critical processes lead to sustainable performance (output). Additionally, the findings should also inspire SMEs to focus even more effort on internal technological and organisational factors and to encourage an ecofriendly culture that would demand stakeholders adopt a more positive environmental stance.
\end{abstract}

Keywords Technological innovations $\cdot$ Green practices $\cdot$ Sustainable performance $\cdot$ Technology-organisation-environment . Resource based view

Mahmood Shah

mahmood.shah@northumbria.ac.uk

Mansour Naser Alraja

malraja@du.edu.om

Rabia Imran

rimran@du.edu.om

Basel M. Khashab

khashab@northumbria.ac.uk

1 Department of Management Information Systems, College of Commerce and Business Administration, Dhofar University, Salalah, Oman

2 Department of Management, College of Commerce and Business Administration, Dhofar University, Salalah, Oman

3 Department of Business, Northumbria University, Newcastle, UK

4 Northumbria University - City Campus, Newcastle, UK

\section{Introduction}

The Covid-19 pandemic dynamically changed the business environment and placed sustainability as a concern for the business world. The business operations that challenge environmental stability and require a physical presence in any form started to face greater risks. Thus, as part of their social responsibility, organisations have adopted environmentally friendly and technologically advanced approaches that result in sustainable performance (Windolph et al., 2014; Zhu et al., 2019). In this regard, changing their product and process portfolios, being proactive, engaging in environmentally friendly practices and using technological innovations to sustain themselves has become a priority for organisations (Seuring \& Gold, 2013). Technological innovations help cope with the pandemic, optimise the use of resources and meet sustainability goals (Klewitz \& Hansen, 2014). The situation requires that organisations adopt new environmentally friendly technologies for sustainable processes and outcomes (Gallego-Álvarez et al., 2011).

Technological innovations can lead to environmentally friendly organisational processes. In the pandemic, 
innovative technologies with an environmental focus are required for sustainable performance. In this scenario, technological innovations help to optimally and effectively utilise scarce resources to create a competitive advantage and control operations remotely (El-Haddadeh, 2020; Klewitz $\&$ Hansen, 2014). The relationship between technological innovations and sustainable performance is complex and depends on numerous factors. One of the most integral factors is the type of innovation that affects business activities and influences specific resources (Sampson, 2007). This situation will increase the competitive advantage and lead to sustainable performance (Chege \& Wang, 2020a). In the current pandemic scenario, all organisations invest in technological innovations to adopt sustainable green practices, such as green HRM, green supply chain, green innovation and green marketing, to achieve sustainable performance.

For more than a decade, developing countries have focused on Small and Medium Enterprises (SMEs) as a strong economic driver (Gbandi \& Amissah, 2014). However, sustainability remains integral due to the slow success rate in the SME sector. Approximately half of SME startups fail within five years, especially in developing countries (Dalberg, 2011; Nikolić et al., 2019). A successful and sustainable SME requires the combination of essential contextual factors such as strong leadership and organisational practices. SMEs may start with enthusiasm and a strong vision, but in order to achieve the outlined performance goals and maintain a competitive advantage, the correct technological support and aligned processes must be in place (Alalawi, 2020; Ayyagari et al., 2007; Teresa Matriano and Firdouse Rahman Khan 2019). With COVID-19 restrictions and lockdowns put in place, the SME sector has faced a huge setback. Due to the requirement for a physical presence, this sector struggled with the new environment and finding ways to achieve sustainability.

The current study adopts the Technology-OrganisationEnvironment (TOE) model developed by Tornatzky and Fleischer (1990). In terms of coping with a dynamically changing environment, the model helps to explore the interplay between inputs, processes and outputs. The TOE framework is flexible and offers the right balance of internal and external drivers to help organisations effectively implement innovations (Aboelmaged, 2014). Few studies have used this framework in the context of sustainability. These studies include green IT initiatives (Hernandez \& Ona, 2015), green supply chain (Hwang et al., 2016) and sustainable manufacturing practices (Aboelmaged, 2018). This model is helpful for developing a holistic framework of sustainable performance by combining several factors that can play their role in achieving sustainable performance. This study conceptualises technological innovation as input, sustainable green practices (such as green HRM, green supply chain, green innovation and green marketing) as process and sustainable performance as output. Additionally, the resource-based view (RBV) theory acts as the theoretical foundation for conducting the study.

The RBV proves relevant in this context for multiple reasons. Firstly, the theory has been used widely in studies of SMEs when measuring sustainability and competitive advantage as they are achievable by understanding the optimal utilisation of scarce and inimitable organisational resources (Barney, 1991; Gile et al., 2018). Secondly, the theory focuses on internal resources and emphasises that those resources can help formulate strategies for achieving targets, such as sustainability (Madhani, 2009). Should these resources prove inimitable and non-substitutable, the organisation would develop a competitive advantage, e.g. digitalisation, that would lead to more sustainable performance (Barney et al., 2001). Thirdly, due to its flexibility, using the TOE framework will allow the incorporation of many technological, organisational and environmental factors (Chege \& Wang, 2020a), moreover, the TOE framework covers the wider context in which technology is used in SMEs (Chege $\&$ Wang, 2020b).

The COVID-19 crisis has affected the world economy in terms of international trade and tourism (Kuckertz et al., 2020). The negative impact spans across all spheres of human life, particularly with regards to health (Sigala, 2020). Most economic activities remain limited due to lockdowns, social distancing, travel restrictions and so on which is a substantial blow to many businesses (Brown \& Rocha, 2020). Businesses and industries of all sizes have been severely impacted due to COVID-19 and are struggling to remain sustainable. However, some businesses have taken this opportunity to find a new niche for themselves, and many SMEs are trying to cope with this changed environment (Bretas \& Alon, 2020). Due to their limited resources, SMEs can be more vulnerable to global crises, and COVID19 is having a particularly harmful effect on them (Utomo et al., 2021). With sustainability becoming one of the most integral factors in the current environment, there remains a need to adopt operations to achieve long-term survival (Mustafa \& Abbas, 2021). This situation pressurises SMEs to improve by employing technologies in order to operate sustainably (Winarsih et al., 2021). The technologies used to develop or adopt green practices lead to sustainability in the industry (Mustafa \& Abbas, 2021). The current research will focus on the mechanism of sustainable performance that SMEs can adopt during the COVID-19 pandemic.

Limited empirical research exists on the effect of technological innovation on sustainable performance through adoption of sustainable green practices in the SME sector (Chege \& Wang, 2020a; D. Singh, Khamba, et al., 2017; Singh, Tan, et al., 2017). To fill this gap, further exploration is required. The average of organisations making use of technology is usually 2 percent (Chege et al., 2020). However, the current 
COVID-19 pandemic has made it inevitable that organisations will shift from traditional to green practices to perform sustainably. For this purpose, SMEs will require customised technologies. The available research on SMEs covers the determinants of the implementation of environmental and social practices, including environment productivity and performance (Rahman \& Post, 2012; Revell et al., 2009), environmental and social practices (Chang et al., 2018), social performance (Sutantoputra, 2009) and green innovation (Arnold, 2017). However, they do not cover the influence of technological innovation on sustainable practices and their effect on SMEs' sustainable performance. The context is generally Western, Asian or African. The specific Middle Eastern region is generally neglected. The current research aims to contribute to both theory and practice by developing a model expected to provide an inclusive theoretical framework for measuring how technological innovation can lead SMEs' sustainable performance levels through adoption of sustainable green practices.

\section{Study Context}

The Sultanate of Oman is one of the prominent members of GCC with a rural and agrarian economy. Oman's population is around 4.56 million with $54.30 \%$ Omani nationals compared to $45.70 \%$ expatriates according to the National Centre for Statistics and Information, 2017 (Imran \& Al-Ansi, 2019). Moreover, the latest data from world bank showed that the Omani GDP reached to 76.33 billion US dollars in 2019 while the GDP value of Oman represents $0.07 \%$ of the world economy (TE, 2021). Oman is characterized by its consistent, systematic and impressive development. Traditionally, its economy has predominantly relied on oil revenues, but recent fluctuations in oil demand and prices have contributed to the use of other sources of income, seeking for more sustainable development (Alraja et al., 2021; Magd $\&$ McCoy, 2014). In addition, the Covid-19 pandemic has resulted in many negative economic impacts worldwide. The Omani economy has also been significantlyaffected, leaving many SMEs suffering. But, according to the International Monetary, the Omani economy is expected to recover in 2021 with a projected growth of 2.5 percent after a 2.8 percent contraction in 2020 with $1.5 \%$ growth from non-oil activities compared to a $3.9 \%$ contraction in 2020 (Kamel, 2021). Furthermore, the pressure on the economy was one of key factors influencing Omani business interests towards sustainable goals. A number of institutions have been established to invest towards a sustainable green economy, including research centers, Sultan Qaboos University, the Innovation and Development Center, Business Incubators and the Scientific Research Council. Moreover, the Environment Society of Oman was established in 2004, which aims to increase environmental awareness and capacity building (Siyabi \& Hakro, 2020). Pressure on governmental resources has reduced, as many initiatives have started materialise, such as technological advancements, promoting private sector investments and encouraging entrepreneurial startups and SMEs (Magd \& El-Gharib, 2021). The country has a large geographical area as compared to its population thus the basic facilities and the technological advancements are required for inter-connectivity in the economy (Alraja et al., 2021). The COVID-19 crisis has further pushed Omani organizations, especially SMEs, to find sustainable ways of conducting business, however the absence of relevant research is hampering progress. This research aims to help bridge this gap and is among the pioneer projects focused on the mechanism of sustainable performance that SMEs can adopt.

\subsection{Theoretical Framework and Hypotheses Development}

The adoption of technological innovations has undergone investigation using different models and theories such as economic theory (Omri, 2020) and open systems theory (Cancino et al., 2018). This study has adopted the Technology-Organisation-Environment (TOE) model developed by Tornatzky and Fleischer (1990) as the primary theoretical underpinning. This model allows organisations to integrate the wider use of technology (Chege \& Wang, 2020a). This framework suggests that the capabilities of the firm to adopt and implement technological innovation depends on three main factors in organizations, namely technological factors, organisational factors and environmental factors. The technological factors in SMEs can be internal and external, for instance, their internal IT infrastructure or the wider external communication infrastructure such as suitable Internet access etc., while the organizational factors can be described as internal, such as management support, size of the firm and ICT innovation intensity, whereas the environmental factors are external such as government regulations, green technologies support infrastructure and pressure from consumer and environment campaigners (Chege \& Wang, 2020a).

Technological innovations are an integral source of sustainable green transformations (Effendi et al., 2020; Yahya et al., 2014). The improvements in technological innovations have led to waste reduction and sustainable green practices (Wang et al., 2021). The sustainable green practices identified in the literature are different and include the green supply chain (Centobelli et al., 2020), green HRM (Mousa \& Othman, 2020), Green marketing (Chung, 2020) and green innovation (Asadi et al., 2020). The current study included a combination (represented in Fig. 1) of these sustainable green practices, including green HRM, green innovation, green marketing and supply chain management. 


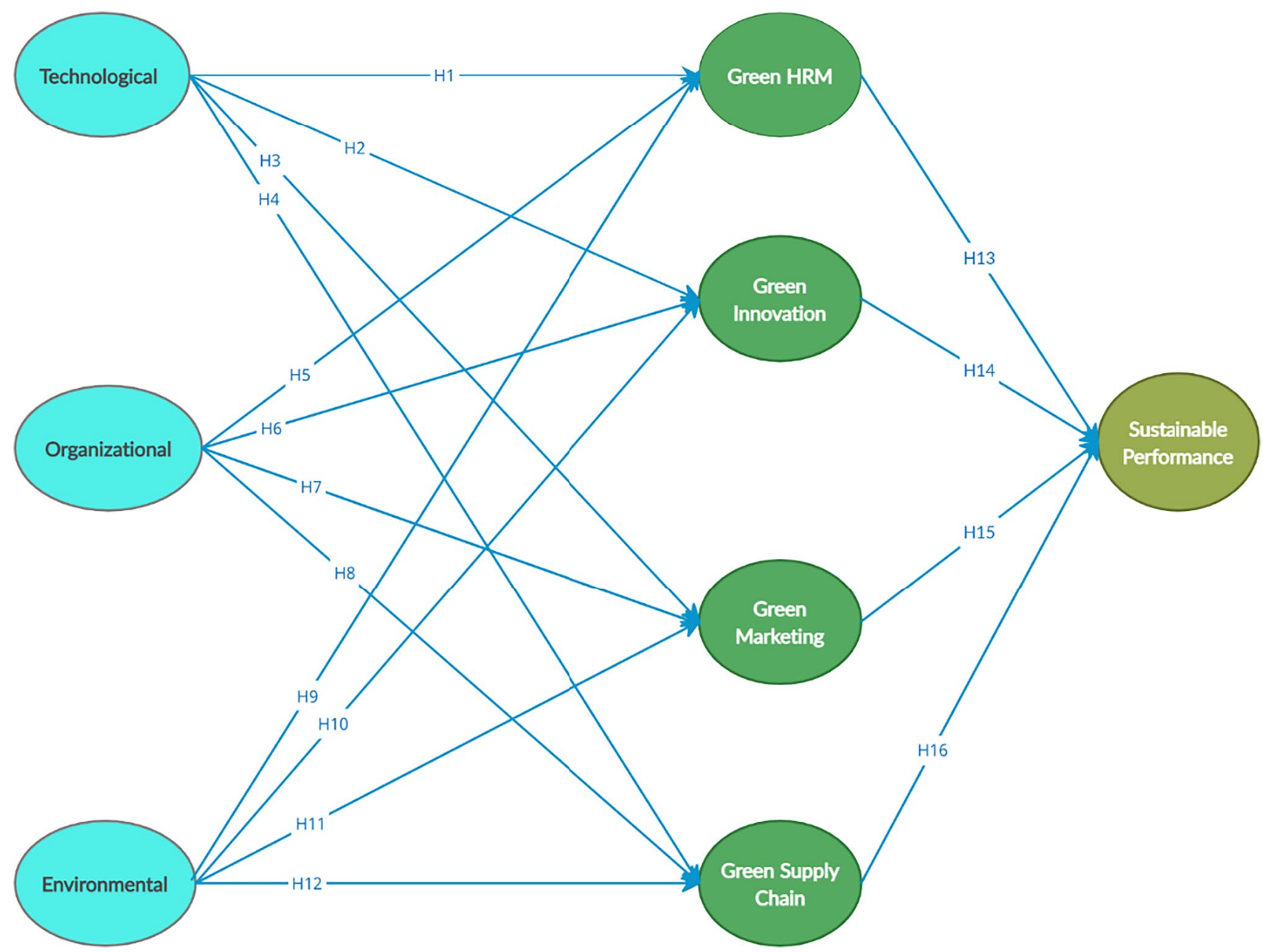

Fig. 1 Proposed model

\subsection{Technological Factors and Sustainable Green Practices}

The technological factors refer to the relevant internal and external technologies for the organization that fits its existing technology landscape (Tornatzky et al., 1990). The frequently used constructs are relative advantage, complexity and compatibility (Grover, 1993; Ramdani et al., 2009). Relative advantage is the advantage gained from the innovation as compared to the one it replaces (Sahin, 2006). Complexity on the other hand, is the perceived difficulty in developing, implementing or utilizing an innovation (Sahin, 2006). Comparability is the consistency of the innovation with the existing worth, experiences and customer needs (Sahin, 2006).

Technological factors improve technological innovation. One of the practices of technological innovation involves adopting a system for environmental management (Lin \& Ho, 2011). There are numerous factors affecting technological innovation (Chege \& Wang, 2020a; S. Singh, Khamba, et al., 2017; Singh, Tan, et al., 2017). However, the current research focuses on the factors of relative advantage and complexity that bear a positive association with maintaining the environmental impact or by the adoption of environmental management systems (Effendi et al., 2020; Lin \& Ho, 2011; Singh Khamba, \& Nanda, 2017; Singh, Tan, et al., 2017). Relative advantage represents one of the technological factors that describes the perceived benefit of the innovation, with organisations tending to adopt technology that demonstrates better performance and high economic gains (Rogers, 2010; Tornatzky \& Klein, 1982). The relative advantage of technological innovations influences innovation adoption and has a positive relationship with the adoption of sustainable green practices (Lin \& Ho, 2011; Singh et al., 2017a, 2017b). Compatibility, on the other hand, represents the perceived consistency of the innovation with firms' prevailing requirements, standards and practices (Everett $\mathrm{M}$. Rogers, 2003). It is relevant to sustainable green practices because the alignment between technological innovations' with existing technologies simplifies the diffusion or adoption of green practices (Etzion, 2007; Lin \& Ho, 2011). 
The technological factors simplify the adoption of sustainable green practices (Thomas et al., 2016). One of the most integral sustainable practices is green HRM. People management takes its inspiration from significant technological advancements. Technological factors are related to the equipment, software and hardware and the ability to introduce new systems (Armstrong \& Taylor, 2017; Yerkes, 2003). The presence of relevant and compatible technological factors not only increases the speed and efficiency of the process but often also minimize the cost and improve the productivity (Marler \& Fisher, 2013). It also eases the process for firms to develop and adopt green HR practices (Rahman et al., 2018; Waheed et al., 2019). The technological factors of the TOE framework relate to the development of organizational infrastructure such as hardware, software and technological equipment (Rahman \& Aydin, 2019; Rahman et al., 2018). Moreover, once the organizations introduce innovative technologies it challenges the status quo and has an effect on organizational operations (Armstrong, 2016). Technological factors also have a strong influence on the adoption of a green supply chain. Such chains facilitate the performance of supply chain practices and improve the coordination and physical flow of information within the system (Omar et al., 2010). The adoption of a green supply chain is a complex process that requires consideration of many aspects (Hsu \& Hu, 2008). The technological factor of the TOE framework demands that organizations to adopt innovations and technologies related to better performance and higher economic gains (Hanna et al., 2021), i.e. how much these technologies are consistent with the present structure and requirements (Rogers, 2010). The fit between the existing system and relevant technologies leads towards the adoption of the green supply chain (Hwang et al., 2016; Savita et al., 2016; Yang et al., 2018).

The rise in the requirement of green concepts and the use of relevant technological factors can also affect green marketing strategies (Chung, 2020). The competition has forced the organizations to adopt green marketing practices (Kumar, 2015). The presence of technological factors makes the adoption of green marketing practices easy in order to meet sustainability goals (Karjaluoto \& Vaccaro, 2009). Organisations' preparations in terms of the availability of technological factors make them capable of innovating and controlling potential dangers (Jones et al., 2005). Thus, the relevant and compatible technological factors facilitate the adoption of green innovation (Chong \& Olesen, 2017; Zhang et al., 2020). The adoption of green innovation practices is largely dependent on the technological factors. The value of the technological factors is dependent on their compatibility with the other technologies needed for green innovations (Zhang et al., 2020). Evidence suggests that the SMEs should make use of technological factors and adopt sustainable green practices, especially during the
COVID-19 pandemic (Chege \& Wang, 2020a; Omri, 2020; Ryoo \& Koo, 2013). Therefore, the following hypotheses are proposed:

Technological factors have a positive effect on adoption of $\left(\mathrm{H}_{1}\right)$ green HRM $\left(\mathrm{H}_{2}\right)$ green innovation $\left(\mathrm{H}_{3}\right)$ green marketing $\left(\mathrm{H}_{4}\right)$ green supply chain.

\subsection{Organisational Factors and Sustainable Green Practices}

In the research on technological innovation, organisational factors account for the second component in the TOE model. Many constructs have been used to define the organisational factors (Chege \& Wang, 2020a; S. Singh, Khamba, et al., 2017; Singh, Tan, et al., 2017). The characteristics of organizational resources including firm size, communication process and management support (Baker, 2012). Some of the important constructs are firm size, top management support and IT skills of non-IT employees (Borgman et al., 2013). In adoption of technological innovations, the most important factor is the size of the organization. Large organizations usually are in a better position to not only invest in innovations but also to facilitate its implementation (Sahin, 2006; Thong, 2015). Top management support is necessary to create a conducive environment and ensure resource provision for technological innovations (Chau \& Jim, 2002; Grover, 1993; Ramdani et al., 2009). The organizational factors of technological innovations are also impacted by the IT skills of non-IT employees; it is the crucial factor in this regard (Chau \& Jim, 2002; Grover, 1993). These variables have a positive association with the adoption of environmental management systems (Effendi et al., 2020; Lin \& Ho, 2011; Singh Khamba, \& Nanda, 2017; Singh, Tan, et al., 2017).

The organizational factors of technological innovations and the adoption of green practices constitute complex processes that require high-level training and human resources development (Del Brío \& Junquera, 2003; Hart, 1995). The efficacy of training programmes depends on the competence and capability of the employees (Russo \& Fouts, 1997). Therefore, the quality of human resources has a positive effect on the adoption of sustainable green practices (Lin \& Ho, 2011; Singh, Khamba, et al., 2017; Singh, Tan, et al., 2017). Adoption of sustainable green practices also depends on the extent of organisational support. Motivated employees demonstrate a greater likelihood to adopt green practices and implement green behaviours. Thus, the presence of organisational support makes the adoption of green practices easy (Lin \& Ho, 2011).

The adoption of sustainable green practices becomes smoother due to the presence of relevant factors. Moreover, the adoption of green HRM requires relevant factors, as HRM symbolises the integral aspect of the organisation. 
The presence of required organisational factors facilitates green HR practices (Rahman et al., 2018; Waheed et al., 2019). The organizational context of the TOE framework refers to the human assets and relevant characteristics such as organizational structure, size and process of communication (Rosli et al., 2012). For implementing green HRM, these factors play an important role (Rahman et al., 2018; Ruël et al., 2004). An organisation's choice to adopt green supply chain practices also necessitates the presence of relevant organisational factors. The presence of qualified human resources and relevant support facilitates the adoption of green supply chain practices (Hwang et al., 2016; Savita et al., 2016). The organisations differ in their internal resources, procedures and ability to respond to challenges. The organizational factors that are unique to an organization can actually build competitive advantage. To adopt green supply chain management practices, the organizational factors play an important role (Hwang et al., 2016). Marketing represents an integral factor in organisational success. Adoption of green marketing practices can enhance sustainability. However, the adoption of green marketing practices requires supportive organisational factors (Chung, 2020). The presence of relevant and supportive organizational factors according to the TOE framework makes it easier for organizations to adopt green marketing practices (Kumar, 2015). Organizational motivation is essential for green innovations (Tsai \& Liao, 2017). The presence of organizational factors necessary for green innovation facilitates its adoption (Aboelmaged \& Hashem, 2019). Organisations competing in an external environment rely on green products and process innovation as a source of competitive advantage. However, it is largely dependent on internal factors. The adoption and implementation of green innovations rely upon the quality of organizational factors (Chong \& Olesen, 2017; Zhang et al., 2020). Therefore, the following hypotheses are proposed:

Organisational factors have a positive effect on adoption of $\left(\mathrm{H}_{5}\right)$ green HRM $\left(\mathrm{H}_{6}\right)$ green innovation $\left(\mathrm{H}_{7}\right)$ green marketing $\left(\mathrm{H}_{8}\right)$ green supply chain

\subsection{Environmental Factors and Sustainable Green Practices}

The environmental factors component of the TOE model indicates the external environment of the organisation. SMEs' willingness to adopt sustainable green practices largely depends upon government support (Lee, 2008). In an uncertain environment, technological innovation will improve organisations' capabilities to adopt sustainable green practices (Aragón-Correa \& Sharma, 2003; Rothenberg \& Zyglidopoulos, 2007).

Environmental factors have a significant impact on the adoption of sustainable green practices. Green human resource management practices cannot be adopted without external support. The organisation committed to adopting green practices may fail in the absence of government support. Therefore, the support of environmental factors facilitates the adoption of green HR practices (Rahman et al., 2018; Waheed et al., 2019). The environmental context of the TOE refers to external environmental issues which are a major push towards adoption of green HRM (Rahman \& Aydin, 2019; Rahman et al., 2018). Supply chain management comprises external activities. Thus, the kind of factors around the organisation can affect the type of supply chain practices adopted. Environmental regulations have emerged as a key driver to the adoption of sustainable green practices (Aboelmaged, 2018). An organisation's decision to adopt green supply chain practices requires the presence of relevant environmental factors (Hwang et al., 2016; Savita et al., 2016). The environmental factors also influence the marketing practices. The relevant environmental factors actually facilitate the adoption of green marketing practices and green marketing practices only prove successful in a supportive external environment. The adoption of green marketing practices requires support from environmental factors (Chung, 2020; Kumar, 2015). The environmental factors push organizations towards adoption of green innovation. The government and legal environmental protection policies have an impact on an organization's innovative practices (Chen et al., 2018; Huang et al., 2016). The process of adoption of green innovation largely depends on the prevailing environmental factors such as support, certainty, policy orientation and market orientation (Zhang et al., 2020). These factors can trigger the kind and type of innovations. Thus, the adoption of green innovations also depends on environmental factors (Chong \& Olesen, 2017; Zhang et al., 2020). Therefore, the following hypotheses are proposed:

Environmental factors have a positive effect on adoption of $\left(\mathrm{H}_{9}\right)$ green HRM $\left(\mathrm{H}_{10}\right)$ green innovation $\left(\mathrm{H}_{11}\right)$ green marketing $\left(\mathrm{H}_{12}\right)$ green supply chain.

\subsection{Sustainable Green Practices and Sustainable Performance}

Sustainability represents one of the most pressing issues in the current climate (Al Hammadi \& Hussain, 2019). The emerging environmental issues constitute a trigger for organisations to find alternative means to survive (Saudi et al., 2019). To succeed in the dynamic business environment, SMEs face overwhelming challenges to implementing sustainable practices (Chang et al., 2018). Their task is to use their limited resources and implement sustainable practices to achieve long-term sustainability (Chege \& Wang, 2020a; Omri, 2020). The resource-based view proposes that the distinctive capabilities and sustainable practices of the 
organisations result in a competitive advantage and sustainable performance levels (Alshehhi et al., 2018).

Past literature, however, is limited in examining the effect between sustainable practices and sustainable performance. Moreover, the literature has taken different sustainable practices, such as environmental practices and green practices, linked with sustainable performance (Borga et al., 2009; Phan et al., 2020; Reyes-Rodríguez et al., 2016). The COVID-19 pandemic completely altered the operating environment. This situation provides the foundation to probe the relationship in detail in this specific situation. Past literature has examined the individual green practices or a combination of two practices, yet a holistic model is absent. The current pandemic has adversely hit organisations, especially SMEs (Block et al., 2021; Fitriasari, 2020) and has highlighted the importance of sustainable performance. Thus, the adoption of sustainable practices represents the only solution to achieve sustainable performance.

Environmental issues are emerging as managerial challenges as organisations struggle to identify ways to reduce negative environmental impact and achieve sustainable performance (Ahmad, 2015; Mancha \& Yoder, 2015). Organisations adopt different sustainable green practices, such as green HRM, to cope with environmental issues and achieve sustainable performance. Green HRM comprises the environmental practices that make organisations more sustainable. These practices ensure sustainable performance (Khan et al., 2021; Mousa \& Othman, 2020). Organisations can achieve sustainable performance through adopting green HRM practice (El-Kassar \& Singh, 2019; Mousa \& Othman, 2020). The emerging environmental issues have forced organisations to shift from traditional to green innovations to survive (Khan et al., 2018; Mohd Saudi et al., 2019).

Enhancing green innovation for corporate sustainability is one of the recent issues globally (Shahzad et al., 2020). Adoption of green innovation practices is interconnected with an organization's environmental schema (Adegbile et al., 2017). Green innovation in both processes and products have a positive effect on not only the environment but also cost reduction and sustainable performance (Singh et al., 2020). Literature suggest that adoption of green innovation practice is an organization's intention towards environmental issues and achieving long-term performance (Kratzer et al., 2017; Lin et al., 2013). The resource-based view also suggests that green innovation can aid competitive advantage and result in sustainable performance (Singh et al., 2020).

One of the ways to ensure sustainable production and consumption and ultimately sustainable development is for businesses to have sustainable or green marketing practices (Fatoki, 2019). Green marketing practices lead to sustainability (Papadas et al., 2017). The adoption of these practices meets environmental concerns. Such practices address environmental challenges and share a link with sustainable performance (Kinoti, 2011). The concept of green marketing has been conceptualized and tested with performance and sustainability in the past (Hasan \& Ali, 2015; Kinoti, 2011; Lam \& Li, 2019) however, there is a need for further in depth exploration.

Nowadays, organizations adopt green supply chain management for addressing the needs of the community and stakeholders. The organisations, in order to sustain themselves, should adopt environmentally friendly green supply chain practices and reach their performance-related outcomes. Green supply chain management practices help organizations to attain their economic and environmental goals and achieve sustainability (Das, 2018). The firms with green supply chain objectives always focus on their suppliers to be green and follow green practices to meet their performance-related objectives (Heras-Saizarbitoria et al., 2011).

The concept of green supply chain management and its relationship with performance has been the center of attention in the past few years (Bon, 2018; Das, 2018; Mitra \& Datta, 2014). The firm-level strategic resources, such as the green supply chain, result in sustainable performance (Fatoki, 2019).

Thus, following hypotheses are proposed:

$\mathrm{H}_{13}$ : green sustainable practices $\left(\mathrm{H}_{14}\right)$ green innovation $\left(\mathrm{H}_{15}\right)$ green marketing $\left(\mathrm{H}_{16}\right)$ green supply chain adoption has a positive effect on sustainable performance.

\section{Methodology}

\subsection{Sample and Data Collection}

SMEs play a vital role in the economy (Alraja et al., 2021), especially in achieving sustainability, as these enterprises have an integral effect on many sustainable development goals (Betti et al., 2018). The research focused on SMEs from different sectors in Oman. Table 1 illustrates the profile of the targeted organisations.

SMEs in Oman are active in all different industries i.e. manufacturing and service industry. SMEs are expected to play a vital role in the economy. During the pandemic, SMEs helped both business and individuals reduce the negative effect on them i.e. SMEs were able to make the vital material and goods available for people, shops and other business. For example, during COVID-19, SMEs focused digital solutions as in person contact was prohibited (Times of Oman, 2021). Compared with 2020, the number of operating SMEs in Oman has increased from 44,139 to 52,524 SMEs (+7000) (NCSI, 2021). However, our research focused on SMEs from different sectors in Oman and different areas of 
Table 1 Enterprises profile

\begin{tabular}{llll}
\hline Characterization & & Frequency & Percent \\
\hline SME Size & $5-9$ employees & 251 & 37.5 \\
& $10-19$ employees & 157 & 23.5 \\
& $20-49$ employees & 201 & 30.0 \\
& $50-99$ employees & 60 & 9.0 \\
SME Age & less than 5 & 351 & 52.5 \\
& 5 to less than 10 & 114 & 17.0 \\
10 to less than 15 & 64 & 9.6 \\
& 15 to less than 20 & 69 & 10.3 \\
& 20 and more & 71 & 10.6 \\
\hline
\end{tabular}

Oman; especially from Muscat, which is home to 17,692 SMEs (the largest in Oman).

We chose a broad sample of SMEs to get input from a wide range of organisations and people working in those. For example, in our sample, $52.5 \%$ were less than 5 years old, $17 \%$ were $5-10$ years old, $9.6 \%$ were $10-15$ years old, $10.3 \%$ were $10-15$ years old and $10.6 \%$ were 20 years old and more. Medium sized enterprises (10-99 workers) made up $63.5 \%$ and small sized enterprises (5-9 workers) made up $37.5 \%$. Furthermore, about $70 \%$ of the respondents are female, while $30 \%$ were male. It has been reported that Omani's total early-stage entrepreneurial activity rate has more than doubled between 2019 and 2020 with a significant increase from $6.7 \%$ to $16 \%$ explaining the increased desire of Omani adults to start a new business in comparison to previous years (GEM, 2020). Numerous studies conducted in developing countries like Oman (Ghouse et al., 2017) found that a female's entrepreneurial skills can be key drivers of the social and economic development (Ghouse et al., 2019); most Omani SMEs are found to be operated by women (GEM, 2005). In 2021, a report by GEM showed that the majority of new Omani firms are regularly expected to be started by female entrepreneurs as the rates have increased by at least $10 \%$ compared to men (Bosma et al., 2021).

Furthermore, about $23 \%$ of the employees were from international backgrounds, and $4.3 \%$ of the targeted SMEs were international enterprises. However, the employees in our sample belong to different units and levels in their SMEs. i.e. about twenty five percent belong to a marketing unit/department, $23.8 \%$ to a human resources unit/department, $19.6 \%$ to an accounting/finance unit/department, $16.4 \%$ to an IT a unit/department, $11.2 \%$ to a customer services unit/department and $3.6 \%$ to a other unit/department (refer to Table 2).

The definition of SMEs tends to rely on the number of employees, meaning the researchers grouped the surveyed

Table 2 Respondents profile

\begin{tabular}{|c|c|c|c|c|}
\hline Characterization & & Frequency & Percent & \\
\hline \multirow[t]{2}{*}{ Gender } & Male & 208 & & 31.1 \\
\hline & Female & 461 & & 68.9 \\
\hline \multirow{2}{*}{$\begin{array}{l}\text { Employee type } \\
\text { (national or inter- } \\
\text { national) }\end{array}$} & National & 517 & & 77.3 \\
\hline & International & 152 & & 22.7 \\
\hline \multirow{2}{*}{$\begin{array}{l}\text { Employees work in } \\
\text { Local or Interna- } \\
\text { tional enterprise }\end{array}$} & Local company & 640 & & 95.7 \\
\hline & International enterprise & 29 & & 4.3 \\
\hline \multirow[t]{6}{*}{ Specialization } & Marketing unit/department & 170 & & 25.4 \\
\hline & Human Resources unit/department & 159 & & 23.8 \\
\hline & Accounting/finance unit/department & 131 & & 19.6 \\
\hline & IT unit/department & 110 & & 16.4 \\
\hline & Customer services unit/department & 75 & & 11.2 \\
\hline & Other unit/department & 24 & & 3.6 \\
\hline \multirow[t]{4}{*}{ Job level } & First Line Employee & 286 & & 42.8 \\
\hline & First Line Manager & 133 & 19.9 & \\
\hline & Middle Level Manager & 169 & 25.3 & \\
\hline & Top Manager & 81 & 12.1 & \\
\hline
\end{tabular}


SMEs into four primary groups to meet the majority definitions. In Oman, small enterprises have between five and nine employees, while medium enterprises employ between 10 and 99 workers (MTC\&IT 2021).

However, the online administered questionnaire was available to respondents in both English and Arabic languages. A purposive sampling procedure took place to select the sample i.e. based on the available list of SMEs, the electronic link of our questionnaire was submitted to all SMEs that have an available email or any other electronic communication method like WhatsApp (this method was adopted to avoid any physical contact between people and maintain social distancing to reduce COVID-19 spread). An introductory paragraph articulated the purpose of the study and defined key terms. Following the Oman definition of SMEs (MTC\&IT 2021), all Omani SMEs that met the identified criteria were targeted purposively. Furthermore, all the employees who belong to one of the following groups 'First Line Employee', 'First Line Manager', 'Middle Level Manager' and 'Top Manager' were encouraged to respond to the online distributed questionnaire. The research model was tested using data collected between March and April 2021.

\subsection{Common Method Bias}

The respondents in this study came from different administrative levels and functional specialisations (see Table 2 respondents' profile) working in Oman's SMEs. However, to avoid any potential common method bias (CMB), the study followed the Ping's (2004) suggested steps before, during and after data collection. To judge consistency, validity and reliability prior to data collection, firstly, a group of experts comprising five academicians and five experts from the SMEs sector reviewed the developed document. Secondly, based on the comments and feedback, the first draft of the questionnaire was modified, with a pilot study then taking place on a purposive sample of 30 employees from SMEs to ensure the validity and reliability of the questionnaire before its distribution for data collection (van Teijlingen \& Hundley, 2002). Subsequently, the final version of the questionnaire was made ready. Afterwards, during data collection, targeted participants received a briefing about the study's aims through a cover letter. This method ensured the participants that their responses would remain anonymous and confidential and would only be used for academic research. Additionally, it encouraged them to answer questions truthfully and reminded them that they could withdraw from the survey at any point. Finally, the study constructs were separated randomly in the final version of the distributed questionnaire. After data collection, researchers implemented Harman's single-factor test to check the presence of CMB. The test showed seven factors, and the highest variance for the first rotated factor was 40.786 percent (Podsakoff et al.,
2012). This variance stood at less than the accepted 50 percent threshold, which indicates no pressing issues related to CMB in the current study (Pinzone et al., 2019).

\subsection{Measures}

This study assessed the connection shared by technological innovation (as inputs) represented by technological, organisational and environmental factors, green practices (as process) represented by green human resources management, green marketing, green innovation and green supply chain, and sustainable performance (as outputs). The study also examined the causal impact of technological innovation on green practices, as well as the impact of green practices on sustainable performance. To examine this conceptual model, a survey instrument was designed using items from some previously developed instruments. This survey underwent translation into Arabic to ensure clarity for participants. The translated version was reviewed by two bilingual faculty members belonging to the same field of the current study to aid understanding for respondents unfamiliar with the English language, thereby helping them select items that reflected their opinion accurately (Alraja et al., 2019, 2020). The measurement was perception-based, and the unit of analysis was individual, with all scales having multiple dimensions. Technological innovation was measured through 18 items divided into three dimensions of technological factors, organisational factor and environmental factors which were measured by seven, six and five items, respectively. These factors were validated by previous research and adopted from (Chege \& Wang, 2020a). Meanwhile, green practices were measured through 22 items divided into four dimensions of green HRM, green marketing, green innovation and green supply chain. Green HRM was evaluated with six items utilised from (Guerci et al., 2016). Moreover, green innovation was assessed using six items adopted from (Aboelmaged \& Hashem, 2019; Chen \& Liu, 2020; Chiou et al., 2011), green marketing was tested using five items adopted from [80], and green supply chain was examined using five items adopted from (Benzidia et al., 2021; Chiou et al., 2011; Singh \& El-Kassar, 2019). Sustainable performance was measured through five items adopted from (Lin et al., 2013).

\subsection{Statistical Analysis Procedure}

The questionnaire was administered online. All the received responses underwent initial scanning using SPSS 23 software. The process brought in 756 questionnaires. After assessing the returned responses and based on the initial scanning, 87 were dropped from the analysis because the questionnaire items had given the same answer (e.g. all questions were strongly agreed or disagreed), and 
in some of them, the size of the enterprise was out of the acceptable range (i.e., more than 4 employees and less than 100). Consequently, the valid questionnaires for analysis were 669 , which accounted for 88.5 percent of completed questionnaires. This sample size fell within the acceptable range for analysis using partial least squares (PLS) (Hair et al., 2016). The structural model of the current study underwent assessment through the partial least squaresstructural equation modelling (PLS-SEM) (Ameen, et al., 2021a, 2021b; Henseler et al., 2009) using the SmartPLS 3.3.3 software.

The final valid data (questionnaires) underwent analysis in two primary phases. The first phases sought to validate the adopted measurement through testing. The skewness and kurtosis test ensured the normal distribution of the utilised items while the composite reliability (CR) and Cronbach's alpha $(\boldsymbol{\alpha})$ tests ensured the internal consistency reliability of the study mode. Then, convergent and discriminant validity tests validated the research model. Prior to carrying out the structural equation modelling test, the multicollinearity test (inner and outer test) took place using the variance inflation factor (VIF) method to determine whether any potential errors could arise due to the high correlations of the latent variables.

\section{Analysis and Results}

\subsection{Measurement Assessment}

The validity of the measurement model underwent appraisal using different types of tests, and the normal distribution was ensured by the statistical tests skewness and kurtosis, with the result for each item falling in the acceptable range +2 to -2 .

Moreover, the outer loading (represented in Table 3) ensures that loadings of all included items exceeded the acceptable threshold $\geq 0.70$ (Hair et al., 2010a). However, the loading value for a few items was $<0.70$, so they were dropped from the analysis. Such items included the technological latent variable: indicators Tech8 (0.639), and Tech9 (0.612); the green innovation latent variable: indicators GI1 (0.691) and GI3 (0.692); the organisational latent variable: item Orga7 (0.635); and the sustainable performance variable: indicator SP1 (0.627). After these eradications from the dataset, the data underwent analysis again, resulting in the indicator reliability of $>0.70$. Appendix 1 shows all measurement items, including those deleted due to the low loading value. Furthermore, all latent variables achieved the cut-off value of $>0.70$ (Hair et al., 2019) for both composite reliability (CR) and Cronbach's alpha $(\alpha)$.
Table 3 Measurement assessment results

\begin{tabular}{|c|c|c|c|c|c|}
\hline Variable & Item & Alpha & CR & AVE & Loadings \\
\hline \multirow[t]{5}{*}{ SP } & SP2 & 0.843 & 0.889 & 0.615 & 0.778 \\
\hline & SP3 & & & & 0.755 \\
\hline & SP4 & & & & 0.812 \\
\hline & SP5 & & & & 0.787 \\
\hline & SP6 & & & & 0.787 \\
\hline \multirow[t]{6}{*}{ GHRM } & GHRM1 & 0.877 & 0.907 & 0.620 & 0.769 \\
\hline & GHRM2 & & & & 0.773 \\
\hline & GHRM3 & & & & 0.821 \\
\hline & GHRM4 & & & & 0.816 \\
\hline & GHRM5 & & & & 0.797 \\
\hline & GHRM6 & & & & 0.744 \\
\hline \multirow[t]{6}{*}{ GI } & GI2 & 0.868 & 0.901 & 0.603 & 0.762 \\
\hline & GI4 & & & & 0.750 \\
\hline & GI5 & & & & 0.752 \\
\hline & GI6 & & & & 0.825 \\
\hline & GI7 & & & & 0.778 \\
\hline & GI8 & & & & 0.790 \\
\hline \multirow[t]{7}{*}{ Tech } & Tech1 & 0.879 & 0.906 & 0.581 & 0.747 \\
\hline & Tech2 & & & & 0.757 \\
\hline & Tech3 & & & & 0.804 \\
\hline & Tech4 & & & & 0.796 \\
\hline & Tech5 & & & & 0.785 \\
\hline & Tech6 & & & & 0.725 \\
\hline & Tech7 & & & & 0.717 \\
\hline \multirow[t]{6}{*}{ Orga } & Orga1 & 0.879 & 0.908 & 0.642 & 0.749 \\
\hline & Orga2 & & & & 0.822 \\
\hline & Orga3 & & & & 0.799 \\
\hline & Orga4 & & & & 0.818 \\
\hline & Orga5 & & & & 0.806 \\
\hline & Orga6 & & & & 0.740 \\
\hline \multirow[t]{5}{*}{ Envi } & Envi1 & 0.866 & 0.903 & 0.651 & 0.796 \\
\hline & Envi2 & & & & 0.787 \\
\hline & Envi3 & & & & 0.842 \\
\hline & Envi4 & & & & 0.827 \\
\hline & Envi5 & & & & 0.782 \\
\hline \multirow[t]{5}{*}{ GSC } & GSC1 & 0.861 & 0.900 & 0.642 & 0.780 \\
\hline & GSC2 & & & & 0.818 \\
\hline & GSC3 & & & & 0.810 \\
\hline & GSC4 & & & & 0.811 \\
\hline & GSC5 & & & & 0.787 \\
\hline \multirow[t]{5}{*}{ GM } & GM1 & 0.828 & 0.879 & 0.593 & 0.792 \\
\hline & GM2 & & & & 0.769 \\
\hline & GM3 & & & & 0.809 \\
\hline & GM4 & & & & 0.771 \\
\hline & GM5 & & & & 0.707 \\
\hline
\end{tabular}




\subsection{Model Validity}

The study model validity was ensured by the convergent validity. The calculated values of the average variance extracted (AVE) for all constructs were $>0.50$ (Fornell \& Larcker, 1981; Hair et al., 2016), (see Table 3), which confirmed convergent validity. Moreover, discriminant validity underwent testing using the following methods:

Firstly, the Fornell-Larcker criterion, as shown in Table 6 (Appendix 2), indicated that the square root of the AVE for each latent variable proved higher than its maximum correlation with other latent variables (Fornell \& Larcker, 1981).

Secondly, the cross-loadings matrix, represented in Table 7 (Appendix 2), showed each indicator the outer loading on its related latent variable proved greater than all its cross-loadings with other latent variables (Hair et al., 2019).

Thirdly, the use of the heterotrait-monotrait (HTMT) ratio (Henseler et al., 2015), compensated for the lack of sensitivity of the Fornell-Larcker criterion and cross-loading methods to document discriminant validity. For all adopted variables, the optimal HTMT values $<0.85$ were achieved, as shown in Table 8 (Appendix 2). Hence, based on the above-conducted tests, the adopted model demonstrates the presence of discriminant validity.

\subsection{Analysis of Structural Model}

Prior to the structural modelling test taking place, the variance inflation factor (VIF) method sought to exclude any potential errors that may originate from high correlations between the adopted latent variables (Hair et al., 2010b). With PLS-SEM, a collinearity issue was indicated by VIF $\geq 3.3$ (Ameen, et al., 2021a, 2021b; Petter et al., 2007). Table 9 (Appendix 2) depict all VIF (outer and inner) values below this threshold. Thus, in addition to the results of Harman's single factor test discussed previously, both results ensure the absence of multicollinearity problems.

Figure 2 shows all path coefficients $(\beta)$ values from the model's construct relationships. A bootstrapping algorithm with 5000 bootstrap samples in PLS was implemented to determine significance (Table 4). Five percent error probability for the $(\beta)$ values was appraised from $t$ and $p$ values, i.e., $\mathrm{p} \leq 0.05$ validated the hypothesis; $\mathrm{t}$ value $>1.96$.

Organisational factors increase green HRM, green innovation, green marketing and green supply chain $(\beta=0.37$, $0.12,0.26 \& 0.37$ respectively). Further, technological factors also enhance green HRM, green innovation, green marketing and green supply chain $(\beta=0.33,0.50,0.17 \& 0.20$ respectively). Furthermore, environmental factors increase green innovation, green marketing and green supply chain

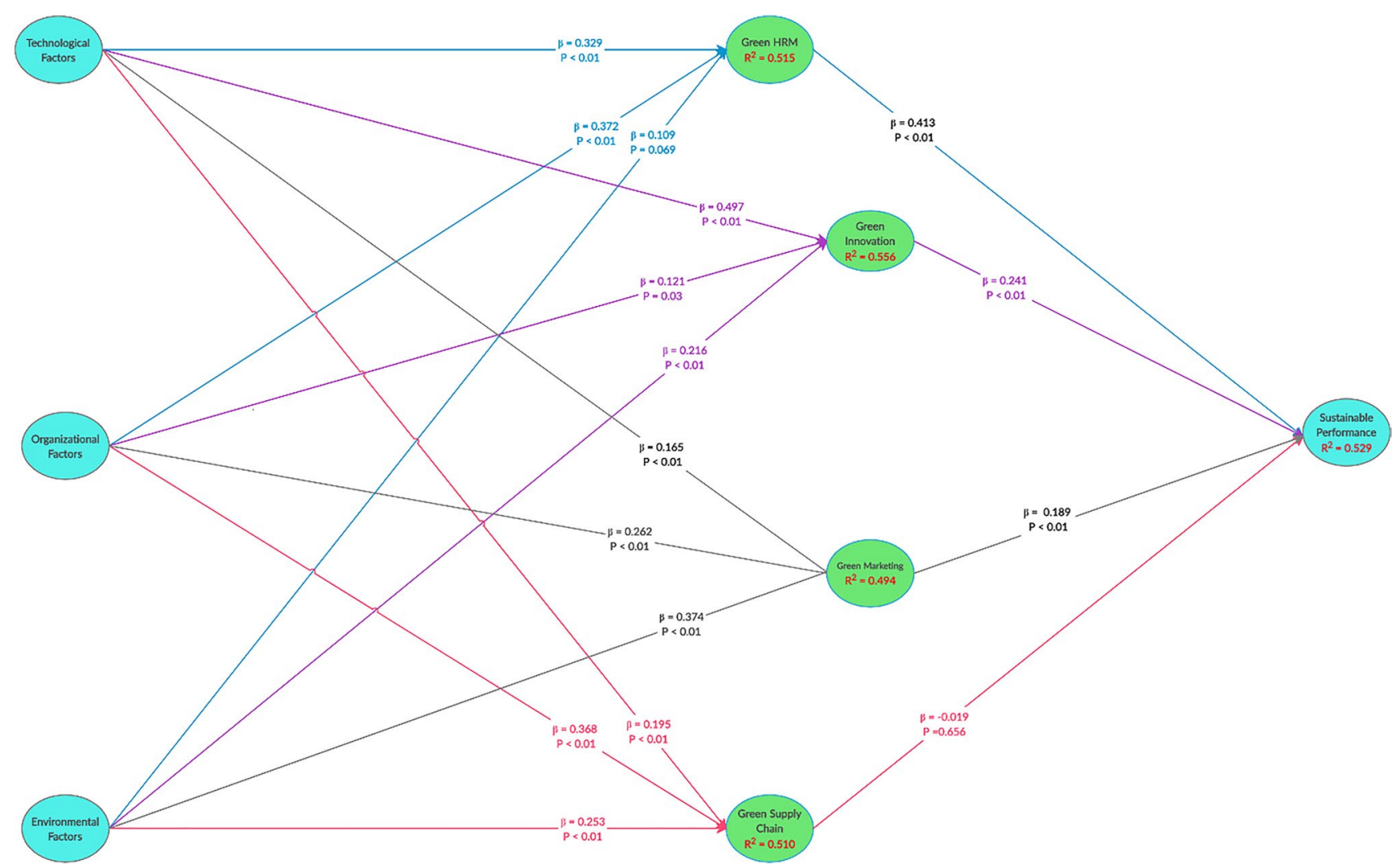

Fig. 2 Structural model path coefficients 
Table 4 Hypotheses test results

\begin{tabular}{|c|c|c|c|c|c|}
\hline Hypothesis & Path & $\beta$ coefficients & T Statistics & P Values & Result \\
\hline H1 & Organizational $\rightarrow$ Green HRM & 0.37 & 6.57 & 0.00 & Support \\
\hline $\mathrm{H} 2$ & Organizational $\rightarrow$ Green Innovation & 0.12 & 2.15 & 0.03 & Support \\
\hline $\mathrm{H} 3$ & Organizational $\rightarrow$ Green marketing & 0.26 & 5.29 & 0.00 & Support \\
\hline $\mathrm{H} 4$ & Organizational $\rightarrow$ Green supply chain & 0.37 & 4.72 & 0.00 & Support \\
\hline H5 & Technological $\rightarrow$ Green HRM & 0.33 & 5.86 & 0.00 & Support \\
\hline H6 & Technological $\rightarrow$ Green Innovation & 0.50 & 9.07 & 0.00 & Support \\
\hline $\mathrm{H} 7$ & Technological $\rightarrow$ Green marketing & 0.17 & 2.98 & 0.00 & Support \\
\hline $\mathrm{H} 8$ & Technological $\rightarrow$ Green supply chain & 0.20 & 2.91 & 0.00 & Support \\
\hline H9 & Environmental $\rightarrow$ Green HRM & 0.11 & 1.85 & 0.07 & Reject \\
\hline $\mathrm{H} 10$ & Environmental $\rightarrow$ Green Innovation & 0.22 & 4.22 & 0.00 & Support \\
\hline H11 & Environmental $\rightarrow$ Green marketing & 0.37 & 8.67 & 0.00 & Support \\
\hline H12 & Environmental $\rightarrow$ Green supply chain & 0.25 & 3.33 & 0.00 & Support \\
\hline H13 & Green $\mathrm{HRM} \rightarrow$ sustainable performance & 0.41 & 7.89 & 0.00 & Support \\
\hline H14 & Green Innovation $\rightarrow$ sustainable performance & 0.24 & 4.26 & 0.00 & Support \\
\hline H15 & Green marketing $\rightarrow$ sustainable performance & 0.19 & 4.24 & 0.00 & Support \\
\hline H16 & Green supply chain $\rightarrow$ sustainable performance & -0.02 & 0.45 & 0.66 & Reject \\
\hline
\end{tabular}

$(\beta=0.22,0.37,0.25 \& 0.41$ respectively). Moreover, green HRM, green innovation, and green marketing improve sustainable performance ( $\beta=0.41,0.24, \& 0.19$ respectively).

On the other hand, environmental factors demonstrated no significant effect on green human resources management $(\beta=0.109 ; p>0.05)$. Additionally, the green supply chain shows no significant effect on sustainable performance $(\beta=-0.019 ; p>0.05)$, meaning the rejection of both $\mathrm{H} 9$ and H16. Meanwhile, the path coefficients $(\beta)$ values and $p$ values for all remaining constructs were significant. Hence, all the remaining hypotheses were supported. Further, the dependent latent variable (sustainable performance) relative to the total variance underwent assessment based on the coefficient of determination, $\mathrm{R}^{2}$. As shown in Fig. 2, about 51.5 percent, 55.6 percent, 49.4 percent and 51 percent of the variance in GHRM, GI, GM and GSC, respectively, was described by technological, organisational and environmental factors. Together, GHRM, GI, GM and GSC explained a 52.9 percent of the variance in sustainable performance.

\section{Discussion}

SMEs experienced setbacks due to the COVID-19 restrictions and faced many challenges to remain sustainable within this fragile environment. This study aimed to measure the impact of SMEs' technological innovation (i.e., technological, organisational and environmental factors) on sustainable performance through sustainable practices such as green HRM, green supply chain, green innovation and green marketing.
This study represents one of the few pieces of pioneering research conducted during the COVID-19 pandemic that developed a holistic framework of sustainable performance, by combining the Technology-Organisation-Environment (TOE) framework and theory of resource-based view (RBV) as the theoretical underpinning. This integration sought to measure SMEs' sustainable performance through green practices in the Middle Eastern region. Our results have shown the importance of environmental factors for green marketing as it has the highest impact level compared to other green practices.

These results are similar to recent study conducted by Chung (2020) indicating that green marketing plays key role in making businesses more competitive by considering environmental factors as drivers for the firm's competitive values as main strategic goals.

While the environmental factors have affected the green supply chain and green innovation, they have shown no significant effect on green HRM. This situation implies that during the COVID-19 pandemic, managers of SMEs might have to decide between operating sustainably or folding as many other businesses did. Therefore, they focus less on the environmental factors concerning HRM practices as this crisis has forced people to work remotely, so they minimise their consumption of resources (raw materials, water and energy) and reduce emissions into the air. Thus, the demand from different environmental context pressures does not necessarily drive the SMEs to involve their employees in environmental issues or select their employees based on environmental criteria, especially under the disruption caused by COVID-19. Equally, minimising consumption of the company resources and its emissions into the air or water 
can influence the adoption of green marketing approaches and methods, such as encouraging the use of e-commerce, using more digital communication methods for promoting their products/services and applying a paperless policy in their procurement.

Although the study by Al-Sheyadi et al. (2019) supports the present belief that GSCM practices can meaningly improve the environmental performance of a business, but the pressure from a specific stakeholder group is one of the key drivers for emerging positive GSC practices. Accordingly, different performance outcomes can be related to the difference in contexts where GSCM practices are implemented. The Omani economy is growing fast where different international companies are operating. However, most of Omani SMEs are relatively smaller and newer i.e. less then 19 employees, and still at early stages of operating and investments i.e. less than 5. Although the Omani economy is growing fast where different international companies are operating, Omani laws and regulations regarding environmental management system (EMS) are still new, and therefore Omani SMEs might need to experience the long term outcomes before implementing GSC (Al-Sheyadi et al., 2019). This can justify why GSC does not improve performance as GSCM implementation practices require time, experienced leadership support and commitment. These findings are in line with Younis et al., (2019) who studied a similar context i.e. UAE and concluded that GSCM practices failed to influence environmental performance and eco-design \& development (Deutz et al., 2013; Zhu \& Sarkis, 2006). Another reason of the lack effect of GSC on sustainable performance is that according to RPT, it is possibly to state that supply chains under crisis are more likely to utilize their uncommon and unique internal resources wisely when framing strategies for achieving their competitive advantages, especially that current competition is more between supply chains comparing the individual companies (Geng et al., 2017). Companies could however share success stories on the benefits and positive effects of GSC practices on sustainable performance, thus encourage other business to adopt more ethical responsibility to protect the planet (Geng et al., 2017).

The majority of the physical/traditional marketing under this crisis has begun its transformation into digital processes. On other hand, in terms of internal factors, the organisational factors affected the green HRM and green supply chain, whereas the green innovation and green supply chain have, respectively, the highest impact on the technological factors. This finding aligns with (Hwang et al., 2016; Rahman et al., 2018). These results further support the idea that when Omani SMEs' top management cares about their societal values and invest more time and effort in adoptung sustainable development practices, they are more likely to provide environmental training and advise their contractors and suppliers to follow the environmental criteria. This situation also accords with the earlier observations of (Hwang et al., 2016; Savita et al., 2016; Zhang et al., 2020).

This study's findings suggest that investing in R \& D to produce high-quality products or using new technology in the production process can help Omani SMEs use more environmentally friendly materials and cleaner or renewable technology to make more savings. This finding was also reported by (Chong \& Olesen, 2017). These results also indicate that Omani SMEs, during the COVID-19 pandemic, use new technology to produce and deliver products and deal with responsible suppliers or subcontractors who adopt environmental criteria and engage in eco-friendly design and development. This finding broadly supports the work of other studies of (Hwang et al., 2016; Zhu et al., 2012) in linking technological factors with the green supply chain practice.

However, the data indicates that green HRM has been influenced by the internal factors (organisational and technological factors) but not the external factors (environmental). Such a situation can result from the internal influence of SMEs managers on organisational and technological factors to cope with the current pandemic. These observational findings suggest that attracting environmentally committed employees and providing environmental training to them is an indication that the Omani companies focus more on the organisational and technological factors.

These results are in agreement with those of (Mousa \& Othman, 2020; Rahman et al., 2018; Waheed et al., 2019) who also found that technological and organizational factors are essential in facilitating the development process when adopting green HR practices.

Another integral finding was that green innovation has been impacted by all factors, with technological factors having the most pronounced effect. Such findings indicate that investing in new technology is essential for SMEs, especially under the current digital transformation culture, which seeks to improve the production process and quality. Prior studies that have noted the importance of technological factors for green innovation are many such as (Chong \& Olesen, 2017; Zhang et al., 2020).

In terms of green marketing, all aspects of the TOE framework have a positive effect, with the external environmental factors having the largest impact while technological factors have the lowest. This situation demonstrates the significance of the imposed legal laws and other external stakeholders during the COVID-19 pandemic for SMEs to market their products/services in a more eco-friendly way using more online e-commerce platforms. This finding broadly supports the work of other studies such as (Chung, 2020 and Kumar, 2015) in this area linking environmental factors with green marketing. 
However, the organisational factors have the highest effect on the green supply chain, while the environmental and technological factors show a medium impact. Rationally, the greater the adoption of sustainable development practices by Omani SMEs in times of crisis, the bigger the chance of advising and selecting suppliers or subcontractors that follow the required environmental criteria. This study supports evidence from previous observations (e.g. Hwang et al., 2016; Savita et al., 2016).

In terms of sustainable SME performance, the green HRM has shown the most positive development among all green practices, while no significant impact was evident between the green supply chain and sustainable SME performance. Moreover, green innovation and green marketing have a positive significance on sustainable SME performance. Hence, during COVID-19, the Omani SMEs that carefully appoint employees based on environmental criteria or/and through environmental commitment and provide training show greater likelihood to increase sustainability, such as by reducing hazardous waste/scrap, cutting the consumption of gasoline/fuel and building partnerships with green organisations and suppliers. In other words, SMEs' performance sustainability is linked strongly with adopting HRM activities that encourage constructive and active environmentally friendly practices.

These findings may help understand the significance of green HRM practices, post-COVID-19, helping Omani SMEs avoid causing future harm by hiring employees who take responsibility for recycling and demonstrate commitment to the environment. These results corroborate the findings of a great deal of the previous work by (Aboelmaged \& Hashem, 2019; J. Chen \& Liu, 2020; Chiou et al., 2011; Muisyo \& Qin, 2021). SMEs can be more sustainable if they improve their environmental compliance and use more environmentally friendly materials when redesigning and enhancing products or services that are easy to recycle, reuse and decompose, as found by (Papadas et al., 2017; Singh et al., 2020). Additionally, investing more in $\mathrm{R} \& \mathrm{D}$ to produce high-quality products and using new production and service delivery procedures will drive more SMEs to perform sustainably. These results align with other research such as (Chen, 2008; Chiou et al., 2011; Muisyo \& Qin, 2021). However, adopting green supply chain activities are found not to contribute to the Omani SMEs' sustainable performance. This result may be explained by the fact that travel restrictions and supply chain disturbances during the COVID-19 pandemic have influenced SMEs' managers' decisions to select suppliers and subcontractors who can supply traditional materials or use more eco-friendly designs.

\section{Implications}

\subsection{Theoretical Implications}

This study developed a holistic framework of sustainable performance by combining a number of factors that showed a robust indication for achieving sustainable performance in SMEs. Integrating the model of the (TOE framework and the theory of RBV has provided a new perspective to measuring sustainability performance, especially through green practices as processes. In other words, the study has extended the TOE framework by adding a new green practices approach that has approved its validity as all TOE framework factors have demonstrated a positive coefficient when measuring the SMEs' sustainability performances. Meanwhile, the TOE framework enables syndication of internal and external factors, whilst adding the green practices in alignment with the RBV has strengthened the theoretical view of sustainability performance. This study's findings designate that green HRM, green innovation and green marketing play an imperative role in sustaining the Omani SMEs' performance during the COVID-19 crisis. This combination provides strong support for the theoretical evidence that green practices as input have a crucial role in the sustainable performance of SMEs. However, green HRM should be the focus for Omani SMEs to sustain their performance. This study's findings show the importance of SMEs' organisational factors when adopting the green supply chain while succeeding in green marketing strategies requires Omani SMEs to focus more on environmental factors. However, as expected, the technological factors are the most essential variables for strategising the green innovation policies.

\subsection{Practical and Academic Implications}

The results of this study inspire the Omani managers of SMEs and policymakers to focus more on the internal factors during the crisis, namely, technological and organisational factors, compared to the external environmental factors, and to encourage an eco-friendly culture in which different internal and external stakeholders adopt more environmental policies and regulations.

They can use this study's findings to proactively develop sustainable performance strategies in response to the environmental rules and laws, especially during the pandemic. Moreover, this study's findings suggest that variables such as green HRM, green marketing and green innovation directly affect sustainability. Therefore, during the pandemic, the managers and policymakers of Omani SMEs should 1) create roles including environmental 
responsibilities; 2) deliver environmental training to employees and managers; 3 ) recruit employees based on environmental criteria; 4) encourage the adoption of cleaner or renewable technology to make more savings; 5 ) focus on redesigning and improving products or services to meet new environmental criteria; 6 ) invest more in enhancing e-commerce and digital communication methods to promote their eco-friendly products/services; and 7) use recycled or reusable materials in their products/ services. These criteria will enable the managers of SMEs to prioritise their internal resources for sustaining their performance.

Moreover, the absence of empirical evidence, and best practices relating to technological innovation, green practices and sustainable performance, will make this paper helpful for educational institutions. Teaching Omani SMEs about sustainability through green practices can help to boost the culture of green practice, especially in times of crisis where academic practical case studies can prove to be limited. Additionally, this study's theoretical framework and the discussed findings can offer valuable knowledge for academic staff when developing curricula and teaching plans.

\section{Limitations and Future Research}

This study has some limitations that could require additional research in future. Firstly, the developed model focused on the direct relationships of the constructs, meaning indirect investigations can help understand the impact of TOE factors on sustainable performance using green practices as moderators. Secondly, our study has used cross sectional data with mainly causality theoretical foundations; a longitudinal approach to future research could undergo investigation as TOE factors might prove different across their study lifecycle. Thirdly, although the studied sample has an adequate number of international companies, the study focused on Oman; by increasing the population to include more countries, new results might emerge and be more generalisable. Fourthly, this research focused on developing countries. Exploring factors affecting SMEs' sustainability factors in Western countries can help create an understanding of the differences and similarities in various locations. Fifthly, our study used purposive sampling due to the inability to construct a comprehensive sampling frame, thus future research might adopt random sampling for better generalisability. Finally, although $68.9 \%$ of our respondents are women, this study did not investigate the gender, size and operated industry as control variables, thus future research might study the role of these variables on sustainable performance.

\section{Conclusion}

This paper contributes to the increasing research in the sustainable performance field for SMEs and adopts the TOE framework factors and resource-based theory view (i.e., green practices) to examine the role of internal green resources on SMEs' sustainable performance. The study has extended the original TOE framework by adding green practices to measure the SMEs' sustainable performance. TOE factors underwent conceptualisation as the input, sustainable green practices, such as green HRM, green supply chain, green innovation and green marketing as the process and sustainability as the output. The motivation to integrate this model was to test how sustainable green practices adoption in SMEs can process the TOE factors when affecting sustainable performance. The existing studies on SMEs, however, cover the determinants of the implementation of environmental and social practices, including environment productivity and performance (Rahman \& Post, 2012; Revell et al., 2009), environmental and social practices (Chang et al., 2018), social performance (Sutantoputra, 2009) and green innovation (Arnold, 2017). However, no previous study has combined the four mentioned green practices based on the RBV perspective to offer an inclusive theoretical framework for determining how the TOE framework can lead SMEs' sustainable performance through green practices.

The results of this study provide clear evidence that technological and organisational factors represent crucial inputs compared to environmental factors for green innovation, green HRM and green marketing when SMEs seek sustainable performance. Specifically, a positive strong relationship is shown between technological factors and green innovation, organisational factors and green HRM and environmental factors and green marketing. Accordingly, adopting recruitment policies based on environmental criteria, namely, being environmentally responsible and committed, require SMEs during the pandemic to invest more time and effort in sustainable development, in addition to paying more courtesy to the environmental and societal values connected with sustainable development. Moreover, redesigned production and operation processes to improve environmental efficiency and improved products or services to meet new environmental criteria require higher investment in $\mathrm{R} \& \mathrm{D}$ and the use of updated technology in the production process, service delivery and marketing. During the pandemic, if SMEs try to endorse the internal culture of minimising their emissions, consumption of resources and the environmental impact of their products, they are more likely to use more eco-friendly products and utilise digital communications methods for promoting products and services. Consequently, SMEs can sustain more during times of crisis to reduce hazardous waste, use more environmentally friendly materials, improve environmental compliance and focus on green HRM and green innovation. 


\section{Appendix 1}

Table 5 Measurement items (including those deleted due to low loading value)

\begin{tabular}{|c|c|c|}
\hline Envi1 & Our company minimizes its consumption of resources (raw materials, water, and energy) & 0.795 \\
\hline Envi2 & Our company minimizes its emissions into the air (greenhouse gases and other substances) & 0.787 \\
\hline Envi3 & Our company minimizes its releases into the water & 0.842 \\
\hline Envi4 & Our company minimizes residual materials & 0.827 \\
\hline Envi5 & Our company minimizes the environmental impact of its products & 0.782 \\
\hline GHRM1 & Our company adhering to select employees based on environmental criteria & 0.769 \\
\hline GHRM2 & Our company adhering to attract employees through environmental commitment & 0.772 \\
\hline GHRM3 & Our company adhering to provide environmental training to the employees & 0.821 \\
\hline GHRM4 & Our company adhering to provide environmental training to the managers & 0.816 \\
\hline GHRM5 & Job description in our company includes environmental responsibilities & 0.798 \\
\hline GHRM6 & Our company adhering to involve its employees in environmental issues & 0.744 \\
\hline GI1 & Our company lower consumption of e.g. water, electricity, gas and petrol during production/use/disposal & 0.691 \\
\hline GI2 & Our company recycle, reuse, and remanufacture materials or parts & 0.779 \\
\hline GI3 & Our company use cleaner or renewable technology to make savings (such as energy, water, waste) & 0.692 \\
\hline GI4 & Our company redesign of production and operation processes to improve environmental efficiency & 0.769 \\
\hline GI5 & Our company redesign and improve products or services to meet new environmental criteria or directives & 0.724 \\
\hline GI6 & Our company uses less or non-polluting/toxic materials that are environmentally friendly & 0.799 \\
\hline GI7 & Our company uses materials that are easy to recycle, reuses, and decompose & 0.734 \\
\hline GI8 & Our company recovers company's end-of-life products and recycling & 0.749 \\
\hline GM1 & We encourage the use of e-commerce, because it is more eco-friendly & 0.792 \\
\hline GM2 & We prefer digital communication methods for promoting our products/services, because it is more eco-friendly & 0.768 \\
\hline GM3 & We apply a paperless policy in our procurement where possible & 0.809 \\
\hline GM4 & We use recycled or reusable materials in our products/services & 0.771 \\
\hline \multirow[t]{2}{*}{ GM5 } & We absorb the extra cost of an environmental product/service & 0.707 \\
\hline & Has your company ever taken the following action with your main suppliers or subcontractors? & \\
\hline GSC1 & Supplier selection on environmental criteria & 0.781 \\
\hline GSC2 & Advising suppliers on environmental technical issues & 0.817 \\
\hline GSC3 & Engaging suppliers in product eco-design \& development & 0.809 \\
\hline GSC4 & Appraising environmental performance of the suppliers & 0.809 \\
\hline GSC5 & $\begin{array}{l}\text { Requiring suppliers or subcontractors to obtain a third-party certification of environmental management system } \\
\text { (EMS) such as ISO } 14000\end{array}$ & 0.789 \\
\hline Orga1 & The adoption of sustainable development practices by your company gives you great pride & 0.741 \\
\hline Orga2 & You care about the environmental and societal values associated with sustainable development & 0.804 \\
\hline Orga3 & $\begin{array}{l}\text { The benefits associated with adopting sustainable development practices are generally greater than the investments } \\
\text { they require }\end{array}$ & 0.795 \\
\hline Orga4 & The time and effort invested in sustainable development has been beneficial to your business & 0.804 \\
\hline Orga5 & You believe that it is your duty to favor the adoption of sustainable development practices by your company & 0.792 \\
\hline Orga6 & Your business environment requires you to adopt sustainable development practices & 0.752 \\
\hline Orga7 & It is important for you to see your company as having adopted sustainable development practices & 0.635 \\
\hline SP1 & Our company adhering to reduce paper use & 0.627 \\
\hline SP2 & Our company adhering to reduce hazardous waste/scrap & 0.776 \\
\hline SP3 & Our company adhering to reduce in consumption of gasoline/fuel & 0.762 \\
\hline SP4 & Our company adhering to build partnership with green organizations and suppliers & 0.789 \\
\hline SP5 & Our company adhering to improve of environmental compliance & 0.77 \\
\hline SP6 & Our company adhering to use environmental friendly material & 0.771 \\
\hline Tech1 & Our company invested in $\mathrm{R} \& \mathrm{D}$ to produce quality products & 0.729 \\
\hline Tech2 & Our company used new technology in the production process & 0.754 \\
\hline
\end{tabular}


Table 5 (continued)

Tech3 Our company used new methods/procedures in production and service delivery 0.777

Tech4 Our company used new technology in marketing new products 0.778

Tech5 Our company market share has increased due to the use of the new technology in marketing 0.76

Tech6 Using technology, we pay only for what we use 0.721

Tech7 Customization using technology is easy 0.707

Tech8 When we use technology, we find it difficult to integrate the existing work with the web based services 0.639

Tech 9 When we perform many tasks together, using technology, it takes up too much of my time 0.612

\section{Measurement Items}

Table 6 Fornell-Larcker

\begin{tabular}{lllllllll}
\hline & Envi & GHRM & GI & GM & GSC & Orga & Tech & SP \\
\hline Envi & $\mathbf{0 . 8 0 7}$ & & & & & & & \\
GHRM & 0.553 & $\mathbf{0 . 7 8 7}$ & & & & & & \\
GI & 0.609 & 0.720 & $\mathbf{0 . 7 7 6}$ & & & & & \\
GM & 0.644 & 0.556 & 0.579 & $\mathbf{0 . 7 7 0}$ & & & & \\
GSC & 0.609 & 0.622 & 0.584 & 0.592 & $\mathbf{0 . 8 0 1}$ & & & \\
Orga & 0.630 & 0.655 & 0.581 & 0.605 & 0.654 & $\mathbf{0 . 7 9 0}$ & & \\
Tech & 0.638 & 0.641 & 0.713 & 0.574 & 0.596 & 0.652 & $\mathbf{0 . 7 6 2}$ & \\
SP & 0.545 & 0.680 & 0.637 & 0.547 & 0.491 & 0.572 & 0.601 & $\mathbf{0 . 7 8 4}$ \\
\hline
\end{tabular}




\section{Appendix 2}

Table 7 Cross-loadings matrix

\begin{tabular}{|c|c|c|c|c|c|c|c|c|}
\hline & Envi & GHRM & GI & GM & GSC & Orga & SP & Tech \\
\hline Envi1 & 0.796 & 0.457 & 0.497 & 0.526 & 0.439 & 0.524 & 0.427 & 0.488 \\
\hline Envi2 & 0.787 & 0.418 & 0.485 & 0.531 & 0.452 & 0.491 & 0.427 & 0.463 \\
\hline Envi3 & 0.842 & 0.418 & 0.482 & 0.510 & 0.476 & 0.508 & 0.431 & 0.566 \\
\hline Envi4 & 0.827 & 0.456 & 0.469 & 0.499 & 0.514 & 0.489 & 0.435 & 0.504 \\
\hline Envi5 & 0.782 & 0.479 & 0.520 & 0.530 & 0.565 & 0.526 & 0.475 & 0.548 \\
\hline GHRM1 & 0.447 & 0.769 & 0.532 & 0.440 & 0.419 & 0.498 & 0.556 & 0.501 \\
\hline GHRM2 & 0.386 & 0.773 & 0.467 & 0.426 & 0.541 & 0.537 & 0.540 & 0.431 \\
\hline GHRM3 & 0.410 & 0.821 & 0.562 & 0.405 & 0.538 & 0.524 & 0.557 & 0.480 \\
\hline GHRM4 & 0.432 & 0.816 & 0.611 & 0.462 & 0.497 & 0.515 & 0.572 & 0.542 \\
\hline GHRM5 & 0.449 & 0.797 & 0.593 & 0.438 & 0.498 & 0.527 & 0.468 & 0.511 \\
\hline GHRM6 & 0.485 & 0.744 & 0.630 & 0.449 & 0.448 & 0.493 & 0.515 & 0.555 \\
\hline GI2 & 0.496 & 0.556 & 0.762 & 0.483 & 0.439 & 0.508 & 0.535 & 0.536 \\
\hline GI4 & 0.433 & 0.585 & 0.750 & 0.435 & 0.525 & 0.505 & 0.515 & 0.521 \\
\hline GI5 & 0.438 & 0.569 & 0.752 & 0.426 & 0.379 & 0.428 & 0.450 & 0.546 \\
\hline GI6 & 0.489 & 0.565 & 0.825 & 0.428 & 0.467 & 0.453 & 0.507 & 0.594 \\
\hline GI7 & 0.507 & 0.500 & 0.778 & 0.470 & 0.450 & 0.408 & 0.433 & 0.544 \\
\hline GI8 & 0.473 & 0.580 & 0.790 & 0.455 & 0.456 & 0.396 & 0.520 & 0.580 \\
\hline GM1 & 0.561 & 0.473 & 0.451 & 0.792 & 0.523 & 0.533 & 0.451 & 0.483 \\
\hline GM2 & 0.489 & 0.415 & 0.406 & 0.769 & 0.398 & 0.500 & 0.421 & 0.444 \\
\hline GM3 & 0.476 & 0.418 & 0.443 & 0.809 & 0.415 & 0.433 & 0.397 & 0.394 \\
\hline GM4 & 0.493 & 0.429 & 0.499 & 0.771 & 0.485 & 0.439 & 0.420 & 0.439 \\
\hline GM5 & 0.450 & 0.397 & 0.432 & 0.707 & 0.450 & 0.411 & 0.413 & 0.443 \\
\hline GSC1 & 0.513 & 0.454 & 0.408 & 0.419 & 0.780 & 0.496 & 0.377 & 0.428 \\
\hline GSC2 & 0.513 & 0.452 & 0.444 & 0.460 & 0.818 & 0.476 & 0.377 & 0.516 \\
\hline GSC3 & 0.478 & 0.535 & 0.493 & 0.487 & 0.810 & 0.541 & 0.421 & 0.498 \\
\hline GSC4 & 0.526 & 0.542 & 0.530 & 0.514 & 0.811 & 0.600 & 0.416 & 0.501 \\
\hline GSC5 & 0.399 & 0.505 & 0.454 & 0.489 & 0.787 & 0.497 & 0.371 & 0.437 \\
\hline Orga1 & 0.461 & 0.506 & 0.464 & 0.458 & 0.516 & 0.749 & 0.437 & 0.557 \\
\hline Orga2 & 0.502 & 0.546 & 0.463 & 0.474 & 0.534 & 0.822 & 0.438 & 0.524 \\
\hline Orga3 & 0.524 & 0.537 & 0.455 & 0.449 & 0.531 & 0.799 & 0.473 & 0.540 \\
\hline Orga4 & 0.516 & 0.514 & 0.471 & 0.472 & 0.557 & 0.818 & 0.467 & 0.513 \\
\hline Orga5 & 0.452 & 0.525 & 0.447 & 0.486 & 0.523 & 0.806 & 0.455 & 0.487 \\
\hline Orga6 & 0.531 & 0.473 & 0.452 & 0.530 & 0.431 & 0.740 & 0.440 & 0.465 \\
\hline SP2 & 0.430 & 0.518 & 0.499 & 0.409 & 0.375 & 0.396 & 0.778 & 0.458 \\
\hline SP3 & 0.398 & 0.499 & 0.466 & 0.418 & 0.332 & 0.415 & 0.755 & 0.430 \\
\hline SP4 & 0.432 & 0.561 & 0.525 & 0.400 & 0.371 & 0.442 & 0.812 & 0.481 \\
\hline SP5 & 0.472 & 0.515 & 0.496 & 0.478 & 0.400 & 0.492 & 0.787 & 0.494 \\
\hline SP6 & 0.405 & 0.570 & 0.509 & 0.438 & 0.439 & 0.491 & 0.787 & 0.491 \\
\hline Tech1 & 0.463 & 0.510 & 0.545 & 0.421 & 0.431 & 0.496 & 0.466 & 0.747 \\
\hline Tech2 & 0.464 & 0.505 & 0.549 & 0.438 & 0.524 & 0.462 & 0.405 & 0.757 \\
\hline Tech3 & 0.529 & 0.481 & 0.565 & 0.448 & 0.464 & 0.488 & 0.504 & 0.804 \\
\hline Tech4 & 0.544 & 0.520 & 0.594 & 0.472 & 0.436 & 0.552 & 0.526 & 0.796 \\
\hline Tech5 & 0.490 & 0.459 & 0.519 & 0.453 & 0.445 & 0.536 & 0.412 & 0.785 \\
\hline Tech6 & 0.421 & 0.457 & 0.528 & 0.422 & 0.460 & 0.450 & 0.410 & 0.725 \\
\hline Tech7 & 0.488 & 0.486 & 0.499 & 0.406 & 0.415 & 0.493 & 0.483 & 0.717 \\
\hline
\end{tabular}


Table 8 HTMT

\begin{tabular}{lllllllll}
\hline & Envi & GHRM & GI & GM & GSC & Orga & Tech & SP \\
\hline Envi & & & & & & & \\
GHRM & $\mathbf{0 . 6 3 3}$ & & & & & & \\
GI & 0.701 & $\mathbf{0 . 8 2 4}$ & & & & & \\
GM & 0.757 & 0.650 & $\mathbf{0 . 6 8 4}$ & & & & \\
GSC & 0.699 & 0.716 & 0.672 & $\mathbf{0 . 6 9 8}$ & & & \\
Orga & 0.722 & 0.747 & 0.664 & 0.706 & $\mathbf{0 . 7 4 8}$ & & \\
Tech & 0.729 & 0.729 & 0.816 & 0.670 & 0.682 & $\mathbf{0 . 7 4 2}$ & \\
SP & 0.636 & 0.789 & 0.743 & 0.653 & 0.573 & 0.663 & $\mathbf{0 . 6 9 7}$ \\
\hline
\end{tabular}

Table 9 VIFs (inner), and $\mathrm{R}^{2}$

Multicollinearity test (VIF inner)

Model's predictive accuracy

\begin{tabular}{llllllr}
\hline Constructs & GHRM & GI & GM & GSC & SP & R $^{2}$ \\
Envi & 1.948 & 1.948 & 1.948 & 1.948 & & Adj R $^{2}$ \\
GHRM & & & & & 2.422 & 0.515 \\
GI & & & & 2.354 & 0.556 \\
GM & & & & 1.793 & 0.494 \\
GSC & & & & & 1.948 & 0.513 \\
Orga & 2.008 & 2.008 & 2.008 & 2.008 & & 0.492 \\
Tech & 2.043 & 2.043 & 2.043 & 2.043 & & \\
SP & & & & & & \\
\end{tabular}

\section{Declarations}

Conflict of Interest Authors have no interests to disclose that are related to the work submitted for publication.

Open Access This article is licensed under a Creative Commons Attribution 4.0 International License, which permits use, sharing, adaptation, distribution and reproduction in any medium or format, as long as you give appropriate credit to the original author(s) and the source, provide a link to the Creative Commons licence, and indicate if changes were made. The images or other third party material in this article are included in the article's Creative Commons licence, unless indicated otherwise in a credit line to the material. If material is not included in the article's Creative Commons licence and your intended use is not permitted by statutory regulation or exceeds the permitted use, you will need to obtain permission directly from the copyright holder. To view a copy of this licence, visit http://creativecommons.org/licenses/by/4.0/.

\section{References}

Aboelmaged, M. (2018). The drivers of sustainable manufacturing practices in Egyptian SMEs and their impact on competitive capabilities: A PLS-SEM model. Journal of Cleaner Production, 175, 207-221. https://doi.org/10.1016/J.JCLEPRO.2017.12.053

Aboelmaged, M. G. (2014). Predicting e-readiness at firm-level: An analysis of technological, organizational and environmental (TOE) effects on e-maintenance readiness in manufacturing firms. International Journal of Information Management, 34(5), 639-651. https://doi.org/10.1016/J.IJINFOMGT.2014.05.002
Aboelmaged, M., \& Hashem, G. (2019). Absorptive capacity and green innovation adoption in SMEs: The mediating effects of sustainable organisational capabilities. Journal of Cleaner Production, 220, 853-863. https://doi.org/10.1016/j.jclepro.2019.02.150

Adegbile, A., Sarpong, D., \& Meissner, D. (2017). Strategic Foresight for Innovation Management: A Review and Research Agenda. International Journal of Innovation and Technology Management, 14(4). https://doi.org/10.1142/S0219877017500195

Ahmad, S. (2015). Green human resource management: Policies and practices. Cogent Business and Management, 2(1), 1030817. https://doi.org/10.1080/23311975.2015.1030817

Al-Sheyadi, A., Muyldermans, L., \& Kauppi, K. (2019). The complementarity of green supply chain management practices and the impact on environmental performance. Journal of Environmental Management, 242, 186-198. https://doi.org/10.1016/J.JENVM AN.2019.04.078

Al Hammadi, F., \& Hussain, M. (2019). Sustainable organizational performance: A study of health-care organizations in the United Arab Emirates. International Journal of Organizational Analysis, 27(1), 169-186. https://doi.org/10.1108/IJOA-10-2017-1263

Alalawi, G. N. S. (2020). The influence of entrepreneurship orientation on omani SMEs' Performance. University of Plymouth. Retrieved from http://hdl.handle.net/10026.1/15412

Alraja, M. N., Farooque, M. M. J., \& Khashab, B. (2019). The effect of security, privacy, familiarity, and trust on users' attitudes toward the use of the IoT-Based Healthcare: The mediation role of risk perception. IEEE Access, 7, 111341-111354. https://doi.org/10. 1109/ACCESS.2019.2904006

Alraja, M. N., Hussein, M. A., \& Ahmed, H. M. S. (2021). What affects digitalization process in developing economies? an evidence from SMEs sector in Oman. Bulletin of Electrical Engineering and Informatics, 10(1). https://doi.org/10.11591/EEI.V10I1.2033 
Alraja, M. N., Khan, S. F., Khashab, B., \& Aldaas, R. (2020). Does facebook commerce enhance SMEs performance? A structural equation analysis of Omani SMEs. SAGE Open, 10(1), 1-14. https://doi.org/10.1177/2158244019900186

Alshehhi, A., Nobanee, H., \& Khare, N. (2018). The impact of sustainability practices on corporate financial performance: Literature trends and future research potential. Sustainability, 10(2), 494. https://doi.org/10.3390/su10020494

Ameen, N., Tarhini, A., Reppel, A., \& Anand, A. (2021a). Customer experiences in the age of artificial intelligence. Computers in Human Behavior, 114, 106548. https://doi.org/10.1016/j.chb. 2020.106548

Ameen, N., Tarhini, A., Shah, M. H., Madichie, N., Paul, J., \& Choudrie, J. (2021b). Keeping customers' data secure: A cross-cultural study of cybersecurity compliance among the Gen-Mobile workforce. Computers in Human Behavior, 114, 106531. https:// doi.org/10.1016/j.chb.2020.106531

Aragón-Correa, J. A., \& Sharma, S. (2003). A contingent resourcebased view of proactive corporate environmental strategy. The Academy of Management Review, 28(1), 88. https://doi.org/10. 2307/30040690

Armstrong, L. (2016). Barriers to Innovation and Change in Higher Education.

Armstrong, M., \& Taylor, S. (2017). Armstrong's handbook of human resource management practice (14th ed.). Kogan Page.

Arnold, M. G. (2017). Corporate social responsibility representation of the German water-supply and distribution companies: From colourful to barren landscapes. International Journal of Innovation and Sustainable Development, 11(1), 1-22. https://doi.org/ 10.1504/IJISD.2017.080655

Asadi, S., OmSalameh Pourhashemi, S., Nilashi, M., Abdullah, R., Samad, S., Yadegaridehkordi, E., et al. (2020). Investigating influence of green innovation on sustainability performance: A case on Malaysian hotel industry. Journal of Cleaner Production, 258, 120860. https://doi.org/10.1016/j.jclepro.2020.120860

Ayyagari, M., Beck, T., \& Demirguc-Kunt, A. (2007). Small and medium enterprises across the globe. Small Business Economics, 29(4), 415-434. https://doi.org/10.1007/s11187-006-9002-5

Baker, J. (2012). The Technology-Organization-Environment Framework. In Y. Dwivedi, M. Wade, \& S. Schneberger (Eds.), Information Systems Theory. Integrated Series in Information Systems, (Vol. 28, pp. 231-245). Springer, New York, NY. https:// doi.org/10.1007/978-1-4419-6108-2_12

Barney, J. (1991). Firm resources and sustained competitive advantage. Journal of Management, 17(1), 99-120. https://doi.org/10.1177/ 014920639101700108

Barney, J., Wright, M., \& Ketchen, D. J. (2001). The resource-based view of the firm: Ten years after 1991. Journal of Management, 27(6), 625-641. https://doi.org/10.1177/014920630102700601

Benzidia, S., Makaoui, N., \& Bentahar, O. (2021). The impact of big data analytics and artificial intelligence on green supply chain process integration and hospital environmental performance. Technological Forecasting and Social Change, 165, 120557. https://doi.org/10.1016/j.techfore.2020.120557

Betti, G., Consolandi, C., \& Eccles, R. (2018). The relationship between investor materiality and the sustainable development goals: A methodological framework. Sustainability, 10(7), 2248. https://doi.org/10.3390/su10072248

Block, A., Gellrich, M., \& Russ, C. (2021). Effects of the COVID-19 Pandemic on SME sustainability: Case study of car dealerships in Switzerland I Block I European Journal of Applied Business and Management. European Journal of Applied Business and Management, 7(1). https://nidisag.isag.pt/index.php/IJAM/artic le/view/547. Accessed 24 April 2021

Bon, A. T. (2018). Green human resource management, Green supply chain management practices and Sustainable performance. In
In 8th International Conference on Industrial Engineering and Operations Management (IEOM) (pp. 6-8). Bandung, Indonesia.

Borga, F., Citterio, A., Noci, G., \& Pizzurno, E. (2009). Sustainability report in small enterprises: Case studies in Italian furniture companies. Business Strategy and the Environment, 18(3), 162-176. https://doi.org/10.1002/bse.561

Borgman, H. P., Bahli, B., Heier, H., \& Schewski, F. (2013). Cloudrise: Exploring cloud computing adoption and governance with the TOE framework. Proceedings of the Annual Hawaii International Conference on System Sciences, 4425-4435. https://doi. org/10.1109/HICSS.2013.132

Bosma, N., Hill, S., Ionescu-Somers, A., Kelley, D., Guerrero, M., \& Schott, T. (2021). Global entrepreneurship monitor (2020/2021) global report.

Bretas, V. P. G., \& Alon, I. (2020). The impact of $<$ scp $>$ COVID $<1$ scp $>-19$ on franchising in emerging markets: An example from Brazil. Global Business and Organizational Excellence, 39(6), 6-16. https://doi.org/10.1002/joe.22053

Brown, R., \& Rocha, A. (2020). Entrepreneurial uncertainty during the Covid-19 crisis: Mapping the temporal dynamics of entrepreneurial finance. Journal of Business Venturing Insights, 14, e00174. https://doi.org/10.1016/j.jbvi.2020.e00174

Cancino, C. A., La Paz, A. I., Ramaprasad, A., \& Syn, T. (2018). Technological innovation for sustainable growth: An ontological perspective. Journal of Cleaner Production, 179, 31-41. https://doi. org/10.1016/j.jclepro.2018.01.059

Centobelli, P., Cerchione, R., \& Esposito, E. (2020). Pursuing supply chain sustainable development goals through the adoption of green practices and enabling technologies: A cross-country analysis of LSPs. Technological Forecasting and Social Change, 153, 119920. https://doi.org/10.1016/j.techfore.2020.119920

Chang, Y., Chen, T. H., \& Shu, M. C. (2018). Corporate social responsibility, corporate performance, and pay-performance sensitivity - evidence from shanghai stock exchange social responsibility index. Emerging Markets Finance and Trade, 54(5), 1183-1203. https://doi.org/10.1080/1540496X.2016.1273768

Chau, P. Y., \& Jim, C. C. (2002). Adoption of electronic data interchange in small and medium-sized enterprises. Journal of Global Information Management (JGIM), 10(4), 61. https:// doi.org/10.4018/JGIM.2002100104

Chege, S. M., \& Wang, D. (2020a). The influence of technology innovation on SME performance through environmental sustainability practices in Kenya. Technology in Society, 60, 101210. https://doi.org/10.1016/j.techsoc.2019.101210

Chege, S. M., \& Wang, D. (2020b). Information technology innovation and its impact on job creation by SMEs in developing countries: An analysis of the literature review. Technology Analysis and Strategic Management, 32(3), 256-271. https:// doi.org/10.1080/09537325.2019.1651263

Chege, S. M., Wang, D., \& Suntu, S. L. (2020). Impact of information technology innovation on firm performance in Kenya. Information Technology for Development, 26(2), 316-345. https://doi.org/10.1080/02681102.2019.1573717

Chen, J., \& Liu, L. (2020). Customer participation, and green product innovation in SMEs: The mediating role of opportunity recognition and exploitation. Journal of Business Research, 119, 151-162. https://doi.org/10.1016/j.jbusres.2019.05.033

Chen, X., Yi, N., Zhang, L., \& Li, D. (2018). Does institutional pressure foster corporate green innovation? Evidence from China's top 100 companies. Journal of Cleaner Production, 188, 304311. https://doi.org/10.1016/J.JCLEPRO.2018.03.257

Chen, Y. S. (2008). The driver of green innovation and green image - Green core competence. Journal of Business Ethics, 81(3), 531-543. https://doi.org/10.1007/s10551-007-9522-1

Chiou, T. Y., Chan, H. K., Lettice, F., \& Chung, S. H. (2011). The influence of greening the suppliers and green innovation on 
environmental performance and competitive advantage in Taiwan. Transportation Research Part e: Logistics and Transportation Review, 47(6), 822-836. https://doi.org/10.1016/j. tre.2011.05.016

Chong, J. L. L., \& Olesen, K. (2017). A technology-organizationenvironment perspective on eco-effectiveness: A meta-analysis. Australasian Journal of Information Systems, 21. https://doi.org/ 10.3127/ajis.v21i0.1441.

Chung, K. C. (2020). Green marketing orientation: Achieving sustainable development in green hotel management. Journal of Hospitality Marketing and Management, 29(6), 722-738. https://doi. org/10.1080/19368623.2020.1693471

Dalberg. (2011). Report on support to SMEs in developing countries through financial intermediaries.

Das, D. (2018). The impact of sustainable supply chain management practices on firm performance: Lessons from Indian organizations. Journal of Cleaner Production, 203, 179-196. https://doi. org/10.1016/J.JCLEPRO.2018.08.250

Del Brío, J. Á., \& Junquera, B. (2003). A review of the literature on environmental innovation management in SMEs: Implications for public policies. Technovation, 23(12), 939-948. https://doi. org/10.1016/S0166-4972(02)00036-6

Deutz, P., McGuire, M., \& Neighbour, G. (2013). Eco-design practice in the context of a structured design process: An interdisciplinary empirical study of UK manufacturers. Journal of Cleaner Production, 39, 117-128. https://doi.org/10.1016/J.JCLEPRO. 2012.08.035

Effendi, M. I., Sugandini, D., \& Istanto, Y. (2020). Social Media Adoption in SMEs Impacted by COVID-19: The TOE Model*. Journal of Asian Finance, Economics and Business, 7(11), 915-925. https://doi.org/10.13106/jafeb.2020.vol7.no11.915

El-Haddadeh, R. (2020). Digital innovation dynamics influence on organisational adoption: The case of cloud computing services. Information Systems Frontiers, 22(4), 985-999. https://doi.org/ 10.1007/s10796-019-09912-2

El-Kassar, A. N., \& Singh, S. K. (2019). Green innovation and organizational performance: The influence of big data and the moderating role of management commitment and HR practices. Technological Forecasting and Social Change, 144, 483-498. https:// doi.org/10.1016/j.techfore.2017.12.016

Etzion, D. (2007). Research on organizations and the natural environment, 1992-Present: A review. Journal of Management, 33(4), 637-664. https://doi.org/10.1177/0149206307302553

Fatoki, O. (2019). Green marketing orientation and environmental and social performance of hospitality firms in South Africa. Foundations of Management, 11(1), 277-290. https://doi.org/10.2478/ fman-2019-0023

Fitriasari, F. (2020). How do small and medium enterprise (SME) survive the COVID-19 outbreak? Jurnal Inovasi Ekonomi, 5(02). https://doi.org/10.22219/jiko.v5i3.11838

Fornell, C., \& Larcker, D. F. (1981). Evaluating structural equation models with unobservable variables and measurement error. Journal of Marketing Research, 18(1), 39. https://doi.org/10. 2307/3151312

Gallego-Álvarez, I., Prado-Lorenzo, J. M., \& García-Sánchez, I. M. (2011). Corporate social responsibility and innovation: A resource-based theory. Management Decision, 49(10), 17091727. https://doi.org/10.1108/00251741111183843

Gbandi, E. C., \& Amissah, G. (2014). Financing options for small and medium enterprises (SMEs) in Nigeria. European Scientific Journal, 10(1), 327-340. 10.1.1.824.4408\&rep=rep1

GEM. (2005). Gender Entrepreneurship Markets (GEM) International Finance Corporation (IFC) GEM Country Brief-OMAN 2005.

GEM. (2020). Entrepreneurship in Oman - GEM Global entrepreneurship monitor. https://www.gemconsortium.org/economy-profiles/ oman-3/policy. Accessed 12 September 2021
Geng, R., Mansouri, S. A., \& Aktas, E. (2017). The relationship between green supply chain management and performance: A meta-analysis of empirical evidences in Asian emerging economies. International Journal of Production Economics, 183, 245-258. https://doi.org/10.1016/J.IJPE.2016.10.008

Ghouse, S. M., McElwee, G., \& Durrah, O. (2019). Entrepreneurial success of cottage-based women entrepreneurs in Oman. International Journal of Entrepreneurial Behavior \& Research, 25(3), 480-498. https://doi.org/10.1108/IJEBR-10-2018-0691

Ghouse, S., McElwee, G., Meaton, J., \& Durrah, O. (2017). Barriers to rural women entrepreneurs in Oman. International Journal of Entrepreneurial Behavior \& Research, 23(6), 998-1016. https:// doi.org/10.1108/IJEBR-02-2017-0070

Gile, P. P., Buljac-Samardzic, M., \& Van De Klundert, J. (2018, August 2). The effect of human resource management on performance in hospitals in Sub-Saharan Africa: A systematic literature review. Human Resources for Health. BioMed Central Ltd. https://doi. org/10.1186/s12960-018-0298-4

Grover, V. (1993). An empirically derived model for the adoption of customer-based interorganizational systems*. Decision Sciences, 24(3), 603-640. https://doi.org/10.1111/J.1540-5915. 1993.TB01295.X

Guerci, M., Longoni, A., \& Luzzini, D. (2016). Translating stakeholder pressures into environmental performance - the mediating role of green HRM practices. International Journal of Human Resource Management, 27(2), 262-289. https://doi.org/10.1080/09585192. 2015.1065431

Hair, J. F., Anderson, R. E., Tatham, R. L., \& Black, W. C. (2010a). Multivariate data analysis (7th ed.). NJ: Prentice-Hall, Inc. https://dl.acm.org/citation.cfm?id=207590. Accessed 3 August 2018

Hair, J. F., Black, W. C., \& Babin, B. J. (2010b). Multivariate data analysis : a global perspective. Pearson Education. https://books. google.com.om/books/about/Multivariate_Data_Analysis.html? id=SLRPLgAACAAJ\&redir_esc=y. Accessed 26 January 2019

Hair, J. F., Hult, G. T. M., Ringle, C. M., \& Sarstedt, M. (2016). A Primer on Partial Least Squares Structural Equation Modeling (PLS-SEM) (2nd ed.). Sage Publishing. https://doi.org/10.1007/ s10995-012-1023-x [doi]

Hair, J. F., Risher, J. J., Sarstedt, M., \& Ringle, C. M. (2019, January 14). When to use and how to report the results of PLS-SEM. European Business Review. Emerald Group Publishing Ltd. https://doi.org/10.1108/EBR-11-2018-0203

Hanna, H., Xirouchakis, P., Rentizelas, A., \& Elbarky, S. (2021). Integrated green supply chain (GSC) adoption model, MENA developing countries empirical study. International Journal of Social Science and Human Research, 04(05). https://doi.org/10.47191/ IJSSHR/V4-I5-11

Hart, S. L. (1995). A Natural-Resource-Based View of the Firm. The Academy of Management Review, 20(4), 986. https://doi.org/10. 2307/258963

Hasan, Z., \& Ali, N. A. (2015). The impact of green marketing strategy on the firm's performance in Malaysia. Procedia - Social and Behavioral Sciences, 172, 463-470. https://doi.org/10.1016/J. SBSPRO.2015.01.382

Henseler, J., Ringle, C. M., \& Sarstedt, M. (2015). A new criterion for assessing discriminant validity in variance-based structural equation modeling. Journal of the Academy of Marketing Science, 43(1), 115-135. https://doi.org/10.1007/s11747-014-0403-8

Henseler, J., Ringle, C. M., \& Sinkovics, R. R. (2009). The use of partial least squares path modeling in international marketing. Advances in International Marketing, 20, 277-319. https://doi. org/10.1108/S1474-7979(2009)0000020014

Heras-Saizarbitoria, I., Landín, G. A., \& Molina-Azorín, J. F. (2011). Do drivers matter for the benefits of ISO 14001? International 
Journal of Operations and Production Management, 31(2), 192216. https://doi.org/10.1108/01443571111104764

Hernandez, A. A., \& Ona, S. E. (2015). Exploring green IT adoption: A case of a business process outsourcing firm. International Journal of Green Computing, 5(2), 13-28. https://doi.org/10.4018/ IJGC.2014070102

Hsu, C. W., \& Hu, A. H. (2008). Green supply chain management in the electronic industry. International Journal of Environmental Science \& Technology 2008 5:2, 5(2), 205-216. https://doi.org/ 10.1007/BF03326014

Huang, X. X., Hu, Z. P., Liu, C. S., Yu, D. J., \& Yu, L. F. (2016). The relationships between regulatory and customer pressure, green organizational responses, and green innovation performance. Journal of Cleaner Production, 112, 3423-3433. https://doi.org/ 10.1016/J.JCLEPRO.2015.10.106

Hwang, B.-N., Huang, C.-Y., \& Wu, C.-H. (2016). A TOE approach to establish a green supply chain adoption decision model in the semiconductor industry. Sustainability, 8(2), 168. https://doi.org/ $10.3390 / \mathrm{su} 8020168$

Imran, R., \& Al-Ansi, K. S. H. (2019). High performance work system, job engagement and innovative work behavior: An exploration in Omani context. In ACM International Conference Proceeding Series (pp. 24-28). Association for Computing Machinery. https://doi.org/10.1145/3328886.3328893

Jones, R. A., Jimmieson, N. L., \& Griffiths, A. (2005). The impact of organizational culture and reshaping capabilities on change implementation success: The mediating role of readiness for change. Journal of Management Studies, 42(2), 361-386. https:// doi.org/10.1111/j.1467-6486.2005.00500.x

Kamel, D. (2021). Oman's economy to expand 2.5\% in 2021, IMF says. https://www.thenationalnews.com/business/economy/2021/09/ 12/omans-economy-to-expand-25-in-2021-imf-says/. Accessed 28 November 2021

Karjaluoto, H., \& Vaccaro, V. L. (2009). B2B green marketing and innovation theory for competitive advantage. Journal of Systems and Information Technology, 11(4), 315-330. https://doi.org/10. 1108/13287260911002477

Khan, N. U., Wu, W., Saufi, R. B. A., Sabri, N. A. A., \& Shah, A. A. (2021). Antecedents of sustainable performance in manufacturing organizations: A structural equation modeling approach. Sustainability, 13(2), 897. https://doi.org/10.3390/su13020897

Khan, S. N., Busari, A. H., Abdullah, S. M., \& Mughal, Y. H. (2018). Followership moderation between the relationship of transactional leadership style and employees reactions towards organizational change. Polish Journal of Management Studies, 17(1), 131-143. https://doi.org/10.17512/pjms.2018.17.1.11

Kinoti, M. (2011). Green marketing intervention strategies and sustainable development: A conceptual paper. International Journal of Business and Social Science, 2(23), 263-273.

Klewitz, J., \& Hansen, E. G. (2014, February 15). Sustainabilityoriented innovation of SMEs: A systematic review. Journal of Cleaner Production. Elsevier. https://doi.org/10.1016/j.jclepro. 2013.07.017

Kratzer, J., Meissner, D., \& Roud, V. (2017). Open innovation and company culture: Internal openness makes the difference. Technological Forecasting and Social Change, 119, 128-138. https:// doi.org/10.1016/J.TECHFORE.2017.03.022

Kuckertz, A., Brändle, L., Gaudig, A., Hinderer, S., Morales Reyes, C. A., Prochotta, A., et al. (2020). Startups in times of crisis - A rapid response to the COVID-19 pandemic. Journal of Business Venturing Insights, 13, e00169. https://doi.org/10.1016/j.jbvi. 2020.e00169

Kumar, P. (2015). Green marketing innovations in small Indian firms. World Journal of Entrepreneurship, Management and
Sustainable Development, 11(3), 176-190. https://doi.org/10. 1108/WJEMSD-01-2015-0003

Lam, J. S. L., \& Li, K. X. (2019). Green port marketing for sustainable growth and development. Transport Policy, 84, 73-81. https:// doi.org/10.1016/J.TRANPOL.2019.04.011

Lee, S. Y. (2008). Drivers for the participation of small and mediumsized suppliers in green supply chain initiatives. Supply Chain Management, 13(3), 185-198. https://doi.org/10.1108/13598 540810871235

Lin, C. Y., \& Ho, Y. H. (2011). Determinants of green practice adoption for logistics companies in China. Journal of Business Ethics, 98(1), 67-83. https://doi.org/10.1007/s10551-010-0535-9

Lin, R. J., Tan, K. H., \& Geng, Y. (2013). Market demand, green product innovation, and firm performance: Evidence from Vietnam motorcycle industry. Journal of Cleaner Production, 40, 101107. https://doi.org/10.1016/j.jclepro.2012.01.001

Madhani, P. M. (2009). Resource based view (RBV) of competitive advantage: an overview. In P. M. M. Madhani (Ed.), RESOURCE BASED VIEW: CONCEPTS AND PRACTICES . ICFAI University Press. https://works.bepress.com/madhani/35/. Accessed 26 August 2020

Magd, H., \& El-Gharib, A. (2021). Entrepreneurship and SMEs Sustainable Development through Business Incubators: The case of Oman Entrepreneurship and SMEs Sustainable Development through Business Incubators: The case of. Scientific Journal for Financial and Commercial Studies and Researches (SJFCSR), 2(2), 191-220.

Magd, H., \& McCoy, M. (2014). Entrepreneurship in Oman: Paving the way for a sustainable future. Procedia Economics and Finance, 15, 1632-1640. https://doi.org/10.1016/S2212-5671(14)00634-0

Mancha, R. M., \& Yoder, C. Y. (2015). Cultural antecedents of green behavioral intent: An environmental theory of planned behavior. Journal of Environmental Psychology, 43, 145-154. https://doi. org/10.1016/j.jenvp.2015.06.005

Marler, J. H., \& Fisher, S. L. (2013, March 1). An evidence-based review of e-HRM and strategic human resource management. Human Resource Management Review. JAI. https://doi.org/10. 1016/j.hrmr.2012.06.002

Mitra, S., \& Datta, P. P. (2014). Adoption of green supply chain management practices and their impact on performance: An exploratory study of Indian manufacturing firms. International Journal of Production Research, 52(7), 2085-2107. https://doi.org/10. 1080/00207543.2013.849014

Mohd Saudi, M. H., Sinaga, O., Gusni, G., \& Zainudin, Z. (2019). The Effect of Green Innovation in Influencing Sustainable Performance: Moderating role of Managerial Environmental Concern. Int. J Sup. Chain. Mgt, 8(1), 303-310. http://www.excelingtech. co.uk/. Accessed 24 April 2021

Mousa, S. K., \& Othman, M. (2020). The impact of green human resource management practices on sustainable performance in healthcare organisations: A conceptual framework. Journal of Cleaner Production, 243, 118595. https://doi.org/10.1016/j.jclep ro.2019.118595

MTC\&IT, M. of T. C. and I. T. (2021). SMEs definition and classification in Oman. ICT SMEs Development Program. https://www. mtc.gov.om/ITAPortal/Pages/Page.aspx?NID=936\&PID=3957\& LID $=184$. Accessed 25 April 2021

Muisyo, P. K., \& Qin, S. (2021). Enhancing the FIRM'S green performance through green HRM: The moderating role of green innovation culture. Journal of Cleaner Production, 289, 125720. https://doi.org/10.1016/j.jclepro.2020.125720

Mustafa, M., \& Abbas, A. (2021). Comparative analysis of green ict practices among palestinian and malaysian in sme food enterprises during Covid-19 pandemic I PalArch's Journal of Archaeology of Egypt / Egyptology. PalArch's Journal of Archaeology 
of Egypt/Egyptology, 18(4). https://archives.palarch.n1/index.php/ jae/article/view/5692. Accessed 24 April 2021

NCSI. (2021). National Centre for Statistics and Information (NCSI).

Nikolić, N., Jovanović, I., Nikolić, D., Mihajlović, I., \& Schulte, P. (2019). Investigation of the factors influencing SME failure as a function of its prevention and fast recovery after failure. Entrepreneurship Research Journal, 9(3). https://doi.org/10.1515/ erj-2017-0030

Omar, R., Lo, M.-C., Yen Sang, T., \& Siron, R. (2010). Information sharing, information quality and usage of information technology (IT) tools in Malaysian organizations. African Journal of Business Management, 4(12), 2486-2499. http://www.academicjo urnals.org/AJBM. Accessed 29 April 2021

Omri, A. (2020). Technological innovation and sustainable development : Does the stage of development matter? Environmental Impact Assessment Review, 83, 106398. https://doi.org/10.1016/j. eiar.2020.106398

Papadas, K. K., Avlonitis, G. J., \& Carrigan, M. (2017). Green marketing orientation: Conceptualization, scale development and validation. Journal of Business Research, 80, 236-246. https://doi. org/10.1016/j.jbusres.2017.05.024

Petter, S., Straub, D., \& Rai, A. (2007). Specifying formative constructs in information systems research. MIS Quarterly: Management Information Systems, 31(4), 623-656. https://doi.org/10.2307/25148814

Phan, T. T. H., Tran, H. X., Le, T. T., Nguyen, N., Pervan, S., \& Tran, M. D. (2020). The relationship between sustainable development practices and financial performance: A case study of textile firms in Vietnam. Sustainability, 12(15), 5930. https://doi.org/10.3390/su12155930

Ping, R. A. (2004). On assuring valid measures for theoretical models using survey data. Journal of Business Research, 57(2), 125-141. https://doi.org/10.1016/S0148-2963(01)00297-1

Pinzone, M., Guerci, M., Lettieri, E., \& Huisingh, D. (2019). Effects of 'green' training on pro-environmental behaviors and job satisfaction: Evidence from the Italian healthcare sector. Journal of Cleaner Production, 226, 221-232. https://doi.org/10.1016/j. jclepro.2019.04.048

Podsakoff, P. M., MacKenzie, S. B., \& Podsakoff, N. P. (2012). Sources of method bias in social science research and recommendations on how to control it. Annual Review of Psychology, 63(1), 539569. https://doi.org/10.1146/annurev-psych-120710-100452

Rahman, M., \& Aydin, E. (2019). Organisational challenges and benefits of e- hrm implementations in governmental organisations: theoretical shift from toe model. International Journal of Economics and Administrative Studies, 127-142. https://doi.org/10. 18092/ULIKIDINCE.516443

Rahman, M., Mordi, C., \& Nwagbara, U. (2018). Factors influencing E-HRM implementation in government organisations: Case studies from Bangladesh. Journal of Enterprise Information Management, 31(2), 247-275. https://doi.org/10.1108/ JEIM-05-2017-0066

Rahman, N., \& Post, C. (2012). Measurement issues in environmental corporate social responsibility (ECSR): Toward a transparent, reliable, and construct valid instrument. Journal of Business Ethics, 105(3), 307-319. https://doi.org/10.1007/s10551-011-0967-x

Ramdani, B., Kawalek, P., \& Lorenzo, O. (2009). Predicting SMEs' adoption of enterprise systems. Journal of Enterprise Information Management, 22(1/2), 10-24. https://doi.org/10.1108/17410 390910922796

Revell, A., Stokes, D., \& Chen, H. (2009). Small businesses and the environment: turning over a new leaf? Business Strategy and the Environment, 19(5), n/a-n/a. https://doi.org/10.1002/bse.628

Reyes-Rodríguez, J. F., Ulhøi, J. P., \& Madsen, H. (2016). Corporate environmental sustainability in danish SMEs: A longitudinal study of motivators, initiatives, and strategic effects. Corporate Social Responsibility and Environmental Management, 23(4), 193-212. https://doi.org/10.1002/csr.1359
Rogers, E. M. (2010). Diffusion of innovations (4th ed.). New York: Simon and Schuster. https://www.simonandschuster.com/books/ Diffusion-of-Innovations-4th-Edition/Everett-M-Rogers/97814 51602470. Accessed 24 April 2021

Rogers, E. M. (2003). Diffusion of Innovations (5th ed.). Free Press.

Rosli, K., Yeow, P., \& Siew, E.-G. (2012). Factors influencing audit technology acceptance by Audit Firms: A New I-TOE Adoption Framework. Journal of Accounting and Auditing: Research \& Practice, 1-11. https://doi.org/10.5171/2012.876814.

Rothenberg, S., \& Zyglidopoulos, S. C. (2007). Determinants of environmental innovation adoption in the printing industry: The importance of task environment. Business Strategy and the Environment, 16(1), 39-49. https://doi.org/10.1002/bse.441

Ruël, H., Bondarouk, T., \& Looise, J. K. (2004). E-HRM: Innovation or irritation. An explorative empirical study in five large companies on web-based HRM. Management Revue, 15(3s), 364-380. https:// www.jstor.org/stable/41783479. Accessed 10 September 2021

Russo, M. V., \& Fouts, P. A. (1997). A resource-based perspective on corporate environmental performance and profitability. Academy of Management Journal, 40(3), 534-559. https://doi.org/ $10.2307 / 257052$

Ryoo, S. Y., \& Koo, C. (2013). Green practices-IS alignment and environmental performance: The mediating effects of coordination. Information Systems Frontiers, 15(5), 799-814. https://doi.org/10.1007/s10796-013-9422-0

Sahin, I. (2006). Detailed review of Rogers' diffusion of innovations theory and educational technology-related studies based on rogers' theory. Turkish Online Journal of Educational Technology - TOJET, 5(2), 14-23.

Sampson, R. C. (2007). R\&D Alliances and firm performance: the impact of technological diversity and alliance organization on innovation. The Academy of Management Journal, 50(2), 364-386. https://doi.org/10.2307/20159859

Saudi, M. H. M., Sinaga, O., Tanjung, G., \& Zainudin, Z. (2019). The effect of green innovation in influencing sustainable performance: Moderating role of managerial environmental concern . International Journal of Supply Chain Management, 8(1), 303-310. https://www.researchgate.net/publication/331813293. Accessed 26 August 2020

Savita, K. S., Dominic, P. D. D., \& Ramayah, T. (2016). The drivers, practices and outcomes of green supply chain management: Insights from ISO14001 manufacturing firms in Malaysia. International Journal of Information Systems and Supply Chain Management, 9(2), 35-60. https://doi.org/10.4018/IJISSCM.2016040103

Seuring, S., \& Gold, S. (2013). Sustainability management beyond corporate boundaries: From stakeholders to performance. Journal of Cleaner Production, 56, 1-6. https://doi.org/10. 1016/j.jclepro.2012.11.033

Shahzad, M., Qu, Y., Zafar, A. U., Rehman, S. U., \& Islam, T. (2020). Exploring the influence of knowledge management process on corporate sustainable performance through green innovation. Journal of Knowledge Management, 24(9), 2079-2106. https:// doi.org/10.1108/JKM-11-2019-0624

Sigala, M. (2020). Tourism and COVID-19: Impacts and implications for advancing and resetting industry and research. Journal of Business Research, 117, 312-321. https://doi.org/10. 1016/j.jbusres.2020.06.015

Singh, D., Khamba, J. S., \& Nanda, T. (2017a). Influence of technological innovation on performance of small manufacturing companies. International Journal of Productivity and Performance Management, 66(7), 838-856. https://doi.org/10.1108/ IJPPM-02-2016-0035

Singh, S. K., \& El-Kassar, A. N. (2019). Role of big data analytics in developing sustainable capabilities. Journal of Cleaner Production, 213, 1264-1273. https://doi.org/10.1016/j.jclepro.2018.12.199

Singh, S. K., Giudice, M. D., Chierici, R., \& Graziano, D. (2020). Green innovation and environmental performance: The role of 
green transformational leadership and green human resource management. Technological Forecasting and Social Change, 150, 119762. https://doi.org/10.1016/j.techfore.2019.119762

Singh, S., Tan, B. C., \& Khan, N. (2017). Driving green practice adoption in restaurant sector: Restaurant operator's perspectives - MMU institutional repository. In Proceedings of the 5th International Conference on Innovation and Entrepreneurship (ICIE 2017) (pp. 219-226). Academic Conferences and Publishing International Limited. http://shdl.mmu.edu.my/7108/. Accessed 24 April 2021

Siyabi, A. S. Al, \& Hakro, D. A. N. (2020). Green economy and sustainable development in the Sultanate of Oman. Journal of Student Research. https://doi.org/10.47611/jsr.vi.915

Sutantoputra, A. W. (2009). Social disclosure rating system for assessing firms' CSR reports. Corporate Communications, 14(1), 34-48. https://doi.org/10.1108/13563280910931063

TE, trading economics. (2021). Oman GDP. https://tradingeconomics. com/oman/gdp. Accessed 28 November 2021

Teresa Matriano, M., \& Firdouse Rahman Khan, M. (2019). Customercentric innovation: case of oman entrepreneurship. International Journal of Management, Innovation \& Entrepreneurial Research, 5(1), 33-39. https://doi.org/10.18510/ijmier.2019.515

Thomas, M., Costa, D., \& Oliveira, T. (2016). Assessing the role of IT-enabled process virtualization on green IT adoption. Information Systems Frontiers, 18(4), 693-710. https://doi.org/10.1007/ s10796-015-9556-3

Thong, J. Y. L. (2015). An integrated model of information systems adoption in small businesses. Journal of Management Information Systems, 15(4), 187-214. https://doi.org/10.1080/07421222. 1999.11518227

Times of Oman. (2021, June 8). SMEs in Oman come to the fore during COVID pandemic - Times of Oman. Times News Service. https://timesofoman.com/article/102336-smes-in-oman-cometo-the-fore-during-covid-pandemic. Accessed 3 September 2021

Tornatzky, L. G., Fleischer, M., \& Chakrabarti, A. K. (1990). The processes of technological innovation. Lexington Books. https:// books.google.com.om/books/about/The_processes_of_techn ological_innovatio.html?id=EotRAAAAMAAJ\&redir_esc=y. Accessed 18 December 2017

Tornatzky, L. G., \& Klein, K. J. (1982). Innovation characteristics and innovation adoption-implementation: a meta-analysis of findings. IEEE Transactions on Engineering Management, EM-29(1), 28-45. https://doi.org/10.1109/TEM.1982.6447463

Tsai, K.-H., \& Liao, Y.-C. (2017). Innovation capacity and the implementation of eco-innovation: Toward a contingency perspective. Business Strategy and the Environment, 26(7), 1000-1013. https://doi.org/10.1002/BSE.1963

Utomo, M. N., Ariska, I., Pratiwi, S. R., \& Kaujan, K. (2021). Strategies for maintaining SMEs performance during Covid-19 pandemic. International Journal of Social Science and Business, 5(1).

van Teijlingen, E., \& Hundley, V. (2002). The importance of pilot studies. Nursing standard (Royal College of Nursing (Great Britain) : 1987). Nurs Stand. https://doi.org/10.7748/ns2002.06.16.40.33.c3214

Waheed, A., Miao, X., Waheed, S., Ahmad, N., Majeed, A., Waheed, A., et al. (2019). How new HRM practices, organizational innovation, and innovative climate affect the innovation performance in the IT industry: A moderated-mediation analysis. Sustainability, 11(3), 621. https://doi.org/10.3390/su11030621

Wang, K. H., Umar, M., Akram, R., \& Caglar, E. (2021). Is technological innovation making world "Greener"? An evidence from changing growth story of China. Technological Forecasting and Social Change, 165, 120516. https://doi.org/10.1016/j.techfore. 2020.120516

Winarsih, Indriastuti, M., \& Fuad, K. (2021). Impact of covid-19 on digital transformation and sustainability in small and medium enterprises (smes): a conceptual framework. In Advances in
Intelligent Systems and Computing (Vol. 1194 AISC, pp. 471476). Springer. https://doi.org/10.1007/978-3-030-50454-0_48

Windolph, S. E., Harms, D., \& Schaltegger, S. (2014). Motivations for corporate sustainability management: Contrasting survey results and implementation. Corporate Social Responsibility and Environmental Management, 21(5), 272-285. https://doi.org/10.1002/csr.1337

Yahya, N., Nair, S. R., \& Kumar Piaralal, S. (2014). Green practices adoption framework for small and medium sized logistics firms in Malaysia. Sains Humanika, 2(3), 79-84. https://doi.org/10. 11113/sh.v2n3.439

Yang, Z., Sun, J., Zhang, Y., \& Wang, Y. (2018). Peas and carrots just because they are green? Operational fit between green supply chain management and green information system. Information Systems Frontiers, 20(3), 627-645. https://doi.org/10.1007/s10796-016-9698-y

Yerkes, L. (2003). How to create a place where people love to work. The Journal for Quality and Participation, 26(4), 47-52.

Zhang, Y., Sun, J., Yang, Z., \& Wang, Y. (2020). Critical success factors of green innovation: Technology, organization and environment readiness. Journal of Cleaner Production, 264, 121701. https://doi.org/10.1016/j.jclepro.2020.121701

Zhu, Q., \& Sarkis, J. (2006). An inter-sectoral comparison of green supply chain management in China: Drivers and practices. Journal of Cleaner Production, 14(5), 472-486. https://doi.org/10. 1016/J.JCLEPRO.2005.01.003

Zhu, Q., Sarkis, J., \& Lai, K. H. (2012). Green supply chain management innovation diffusion and its relationship to organizational improvement: An ecological modernization perspective. Journal of Engineering and Technology Management - JET-M, 29(1), 168-185. https://doi.org/10.1016/j.jengtecman.2011.09.012

Zhu, Q., Zou, F., \& Zhang, P. (2019). The role of innovation for performance improvement through corporate social responsibility practices among small and medium-sized suppliers in China. Corporate Social Responsibility and Environmental Management, 26(2), 341-350. https://doi.org/10.1002/csr.1686

Publisher's Note Springer Nature remains neutral with regard to jurisdictional claims in published maps and institutional affiliations.

Mansour Naser Alraja received the $\mathrm{PhD}$ degree in management information systems (2010). He is currently an associate professor of management information systems (MIS) with the Department of MIS, College of Commerce and Business Administration, Dhofar University, Oman. His research interests include information technology adoption, data analytics, information security, e-commerce, and the IoT. Alraja published many papers in many reputable journals that are indexed in Web of Science that have good impact factor as well as ABS $3 *$ ranked. He has also served as a reviewer for many well-reputed conferences, including AOM, AIB, and IEEE conferences, as well as acting as a reviewer for several reputable journals such the journal of Information Technology and People (IT\&P), journal of Small Business \& Entrepreneurship, IEEE Access, and Sage open. He is College's Chief Accreditation Officer for AACSB. Moreover, since 2018, he has been appointed as the Chair for the Department of MIS. $\mathrm{He}$ is principle investigator for many funded projects.

Rabia Imran $(\mathrm{PhD})$ is currently working as an Associate Professor at Department of Management, College of Commerce and Business Administration, Dhofar University, Salalah, Oman. Her current job responsibilities include teaching, supervision, research, committee, community work and general administration. She received her $\mathrm{PhD}$ degree in Management Sciences in 2010 and has been actively involved in research. Her areas of research contribution and interest include Leadership, Performance, HR practices especially HighPerformance Work Systems, Green Practices, Organizational and individual characteristics, and Innovation. She has published in reputable journals and conferences with indexing in Scopus and web of science. She has also served 
as reviewer of reputable journals and conferences such as AOM and AIB. She has successfully supervised a $\mathrm{PhD}$ thesis and is performing supervisory role for doctorate and master and undergraduate researchers. She has managed and mentored few funded research projects and is currently leading one. She has been leading Department of Management and mentoring junior faculty members. She is involved internal and external programs reviews and has been in board of studies of different universities.

Basel Khashab is a senior lecturer of information system management at the Northumbria University. He is also a programme leader for project management course. He was previously with the University of West London, before joining the Plymouth university as a Lecturer in E-commerce (Digital Innovation and Creative Enterprise Department). Basel is a reviewer for journals such Information Technology and People and Journal of Marketing of Higher education. He is an external reviewer/ panel member to validate business management programme at Liverpool john moores/Dhofar university. Basel has also published several papers in very good Journals such as IEEE, Sage open, and journal of strategic marketing.His areas of interests include digital marketing, virtual reality, healthcare informatics, customer relationship management (CRM), enterprise resource planning (ERP), design science methodology, and higher education technologies.
Mahmood Shah is an Associate Professor of Information Management at the Newcastle Business School, and co-chair of BAME. He is also a Senior Editor of Information Technology and People Journal (ABS $\left.3^{*}\right)$. His present research interests include identifying theft prevention in online retailing and e-banking, as well as Health information systems and IS strategy. He has published several books in the area of information security, e-banking and mobile technologies. He has also published many papers in high quality journals, such as the Computer and Human Behaviour, Information Technology and People, European Journal of Information Systems, International Journal of Simulation Modelling, Health Informatics and the International Journal of Information Management. He also acts as a reviewer for journals such as the British Journal of Management, Information Technology and People and the International Journal of Operations and Production Management. He is a guest editor for a special issue of Information Technology and People on cyber-crimes prevention and a special issue of Computer and Human Behaviour on e-marketing. He has successfully supervised $14 \mathrm{PhD}$ students in the past and is supervising a further three at present. 